\begin{abstract}
MORALES, LUCIA. Determining the Economics of New Moulder Configurations. (Under the direction of Richard Lemaster.)

The moulder is one of the most used machines in the wood industry. It is used to cut stock with rough dimensions to a finished width, a finished thickness and a finished crosssectional shape in one pass, making it cost effective to produce mouldings, floors, door and window components, furniture and other products that we use everyday. Since its invention, the moulder has gone through several changes. Today’s moulders are faster, more flexible, more versatile, more precise, safer and more productive. This research highlights the different technical aspects of the modern moulder and presents an economic calculator that will help the user determine the economic impact of choosing different moulder configurations.
\end{abstract}

The economic calculator is based on the examination of the technical and economic aspects of the moulder from the literature review and consultation with machine experts and users. It has been validated by international machining experts and a leading moulder manufacturer.

The Moulder Economic Calculator (MEC) Program uses Labview ${ }^{\mathrm{TM}}$ and requires a basic knowledge of the machine capabilities and of the production requirements. It is based on economic considerations of the wood machining process. The MEC program uses input data on machine price and purchase method, machine configuration (feed speed, spindle speed, type of tool clamping system, type of spindle positioning indicators, tool design, etc.), production parameters (number of shifts per year, length of shifts, etc.) and production costs (tools, maintenance, labor). The MEC program gives three types of outputs: surface quality 
(knife marks, pitch height), productivity (setup time and possible jobs) and costs (machine, labor, setup, tooling, power consumption and maintenance).

The MEC program is a flexible tool that allows the user to estimate the cost of machining one linear foot of wood with a particular machine configuration, production parameters and production costs. Some capabilities of the MEC program include determining the effect of machine price on machining cost, the effect of setup time on production time and the effect of machine configuration on machining cost. In this way, the MEC program serves the user to compare between different machine configurations and determine which one is best based either on cost, production or flexibility. 


\title{
DETERMINING THE ECONOMICS OF NEW MOULDER CONFIGURATIONS
}

By

\section{LUCIA MORALES}

\author{
A thesis submitted to the Graduate Faculty \\ at North Carolina State University \\ in partial fulfillment of the \\ requirements for the Degree of \\ Master of Science in \\ WOOD AND PAPER SCIENCE
}

Raleigh, North Carolina

2006

APROVED BY:

Dr.Thom J. Hodgson

Dr. Steve D. Jackson

Dr. Richard L. Lemaster

Chair of Advisory Committee 


\section{BIOGRAPHY}

Lucía Morales is originally from Guatemala. She received the Bachelor of Science in 2001 and graduated Cum Laude with the degree of Licentiate in Forestry in 2002 from Universidad del Valle de Guatemala. After her studies, she worked for two years for TECNOMADERAS, S.A. selling wood working machinery and tools in Central America. In 2004 she was granted the Fulbright Scholarship to pursue a Master in Wood and Paper Science at North Carolina State University. She did her research at the Wood Machining and Tooling Research Program and she had the privilege of representing the program and the university at the International Woodworking Machinery and Furniture Supply Fair in Atlanta (2005), the Carolinas Industrial Woodworking Expo in Greensboro (2005), the Forest Products Society 59th International Convention in Quebec (2005), the Association of Woodworking \& Furnishings Suppliers Fair in Las Vegas (2005), the Carolinas Industrial Woodworking Expo in Greensboro (2006), and the Forest Products Society $60^{\text {th }}$ International Convention in New Port Beach (2006).

She has recently accepted a position as export and sales specialist at Holz-Her USA in Charlotte, North Carolina. 


\section{ACKNOWLEDGMENTS}

My special thanks to:

- My advisor, Dr. Richard L. Lemaster for his support and guidance, but especially for his friendship.

- Dr. John Stewart for his ideas on inputs and outputs for the MEC program.

- Mr. Victor Cortes and Mr. Tony Cannon from Weinig USA for their feedback.

- Mr. Hubert Klein from Michael Weinig AG, Mr. Robert Koenigsfeld from SK- USA, Inc., Dr. Johannes Tröger from Stuttgart University and J.R. Powell from Weinig, USA for their explanations on moulder features and operations.

- Timothy Finger at Great Lakes Custom Tool Mfg., Inc., for his presentation on HSK for moulders.

- Marco Pedronici from SCM for providing brochures of SCM moulders.

- Tecnomaderas, for the brochures and CD’s and for introducing me into the world of wood machining..

- The companies from the WCMA that provided information on their machines and production.

- Dr. Steve Jackson and Dr. Thom Hodgson for being part of my committee.

- Mr. Timothy Horn for his information on runout in woodworking tools.

- Mr. Daniel Saloni and Adriana Cardenas for their advice and for being my friends and making my stay at the WMTRP fun.

- My family for their constant encouragement and love. 


\section{TABLE OF CONTENTS}

LIST OF TABLES

vii

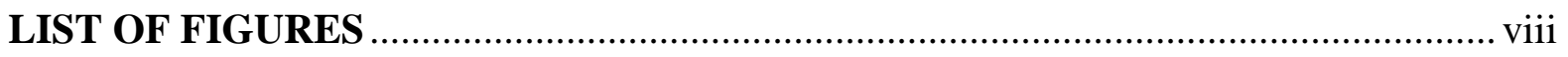

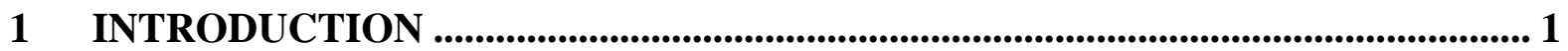

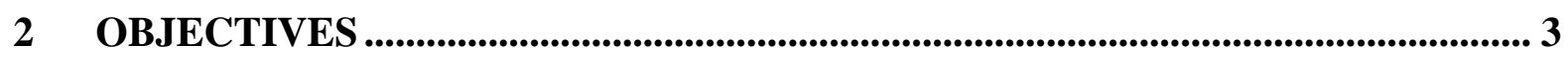

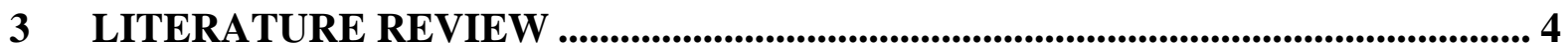

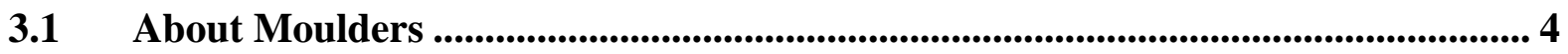

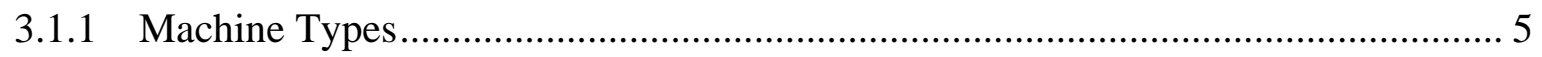

3.1.2 Machine Characteristics .................................................................................... 6

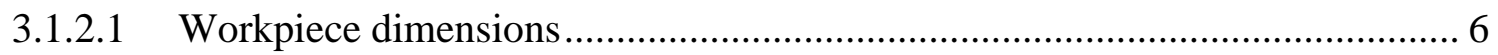

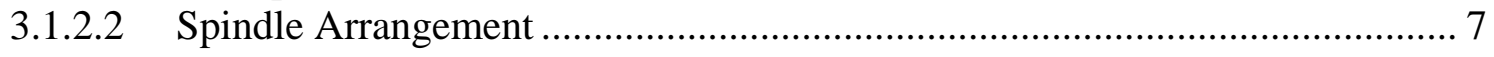

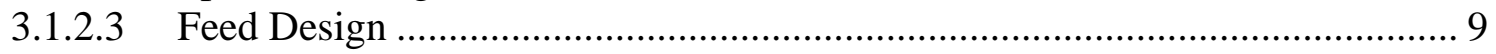

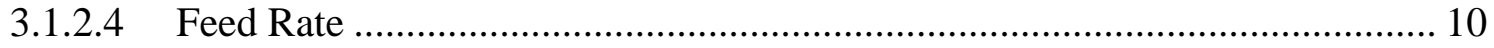

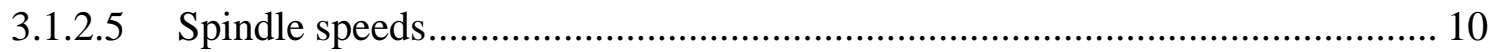

3.1.2.6 Tools and Clamping Systems..................................................................... 11

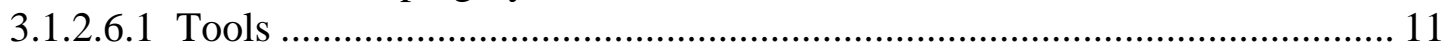

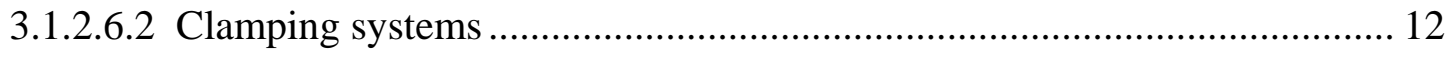

3.1.2.6.2.1 Jointing .............................................................................................. 13

3.1.2.6.2.2 Self-Centering and Clamping System ………...................................... 15

3.1.2.6.2.3 Keyway System ................................................................................. 16

3.1.2.6.2.4 Hydro ……………………............................................................. 17

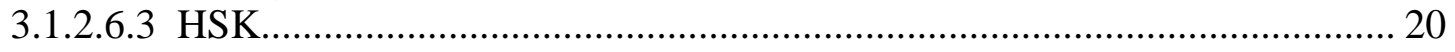

3.1.2.6.4 Other clamping systems .......................................................................... 24

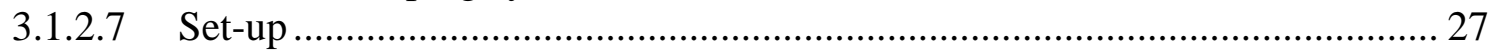

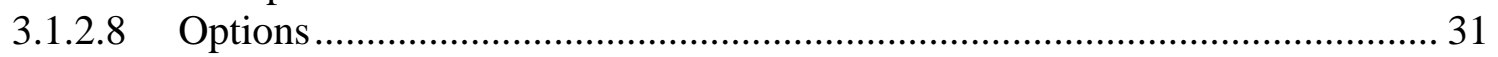

3.1.2.8.1 Grooved bed........................................................................................... 31

3.1.2.8.2 Tiltable Spindles ................................................................................. 32

3.1.2.8.3 Universal Spindles .................................................................................... 32

3.2 Peripheral milling parallel to grain.................................................................................. 33 


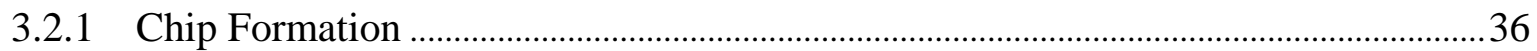

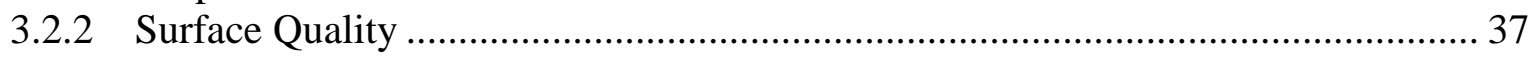

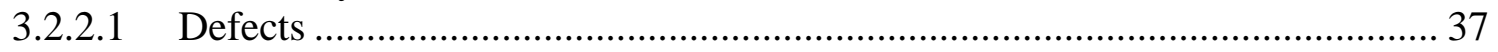

3.2.2.2 Defect Control................................................................................. 38

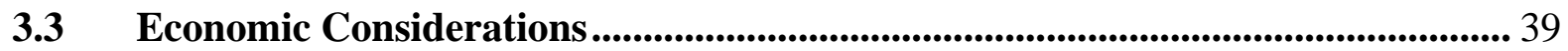

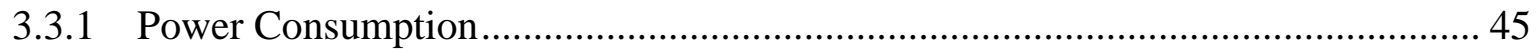

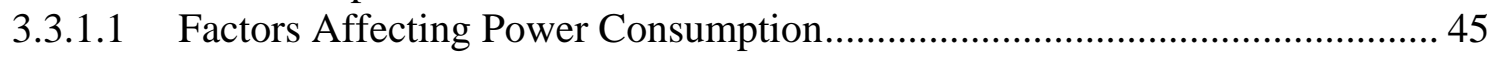

3.3.1.2 Power Consumption Estimation ............................................................... 48

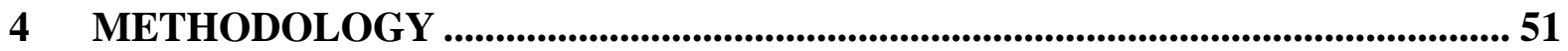

4.1 Moulder Economic Calculator (MEC) Program ...................................................... 51

4.1.1 MEC Program Inputs ................................................................................... 52

4.1.1.1 Machine Price ....................................................................................... 52

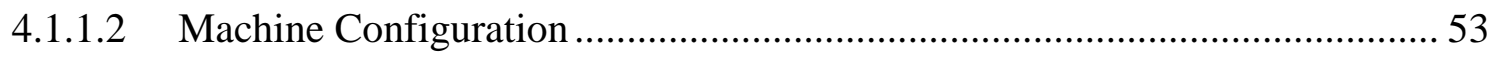

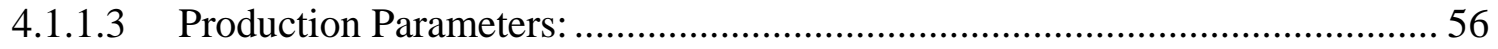

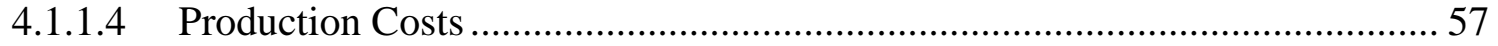

4.1.2 MEC Program Outputs ................................................................................ 58

4.1.2.1 Surface Quality: ................................................................................ 58

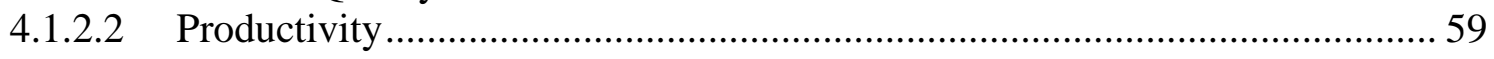

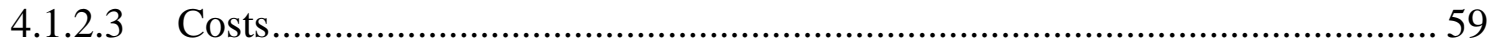

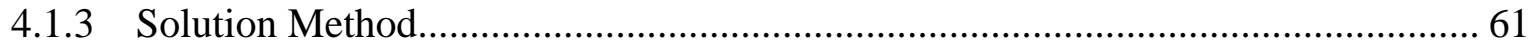

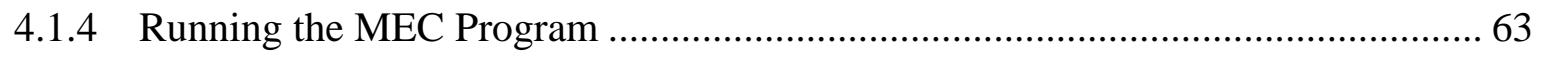

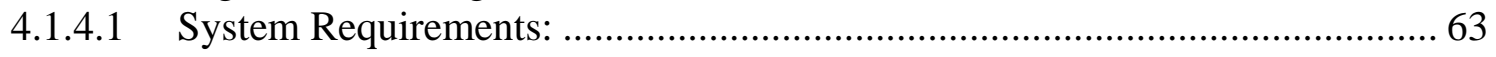

4.1.4.2 Step-by-Step Installation Guidelines: ................................................... 63

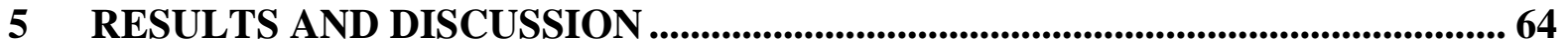

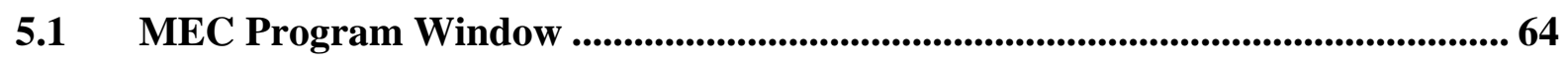

5.2 MEC Program Examples .................................................................................6 65

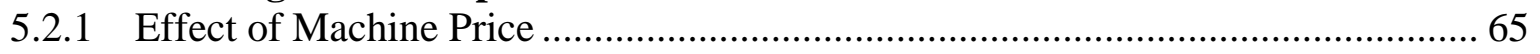

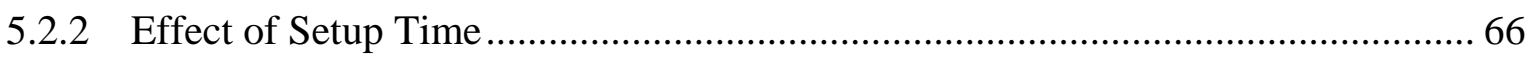

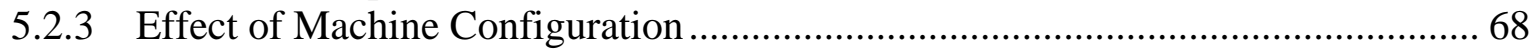

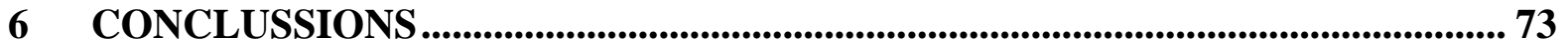

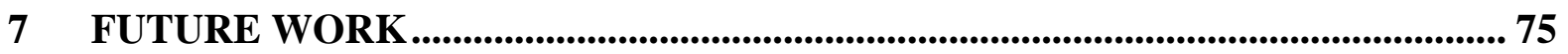




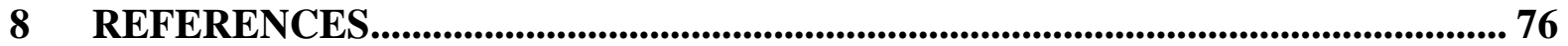

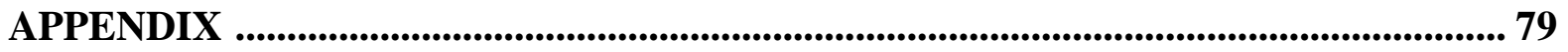




\section{LIST OF TABLES}

\section{Table}

1 Reference parameter values for use in power prediction equation for conventional

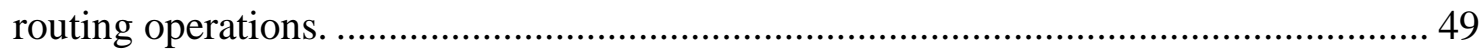

2 Power exponents and multipliers used in the power prediction model for conventional

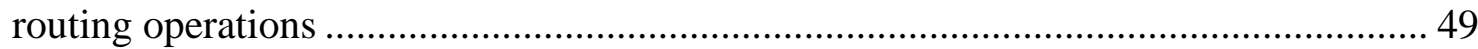

3 Recommendation of feeders according to feed speed and board length ...................... 55

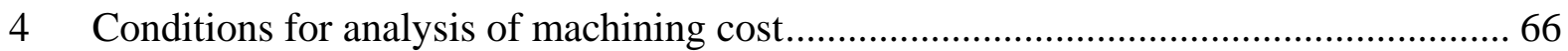

5 Six different machine configurations for small production and few jobs..................... 69 
viii

\section{LIST OF FIGURES}

\section{Figure}

1 Different profiles made on a moulder.............................................................. 4

2 Devices that hold and move the workpiece through the moulder.................................. 5

3 Side view of pressure bar and chipbreaker ......................................................... 5

4 Picture of early moulder vs. Picture of modern moulder............................................ 6

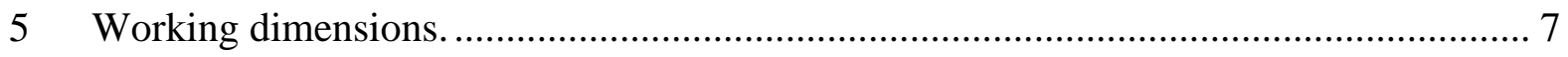

6 1) workpiece before going through the moulder, 2) first reference plane made by first

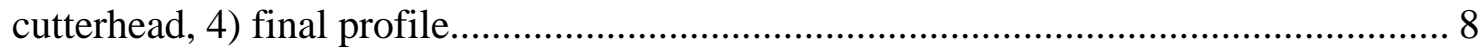

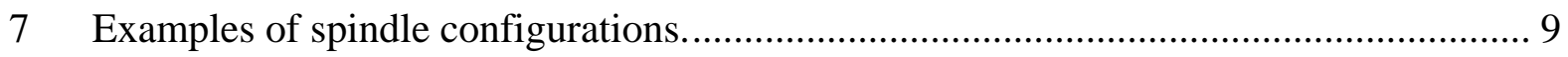

8 Radial static runout condition for a cutterhead (left) and axial static runout condition for a circular saw blade (right). The path traced $b$ the cutting tool is indicated.................. 13

9 a) knives honed with jointing stone to the same cutting circle. B) jointing chamfer or joint land on the knife as a result from jointing. .................................................. 14

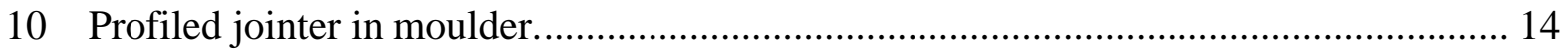




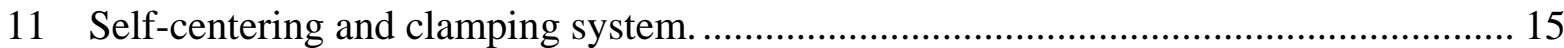

12 a) fit tolerance between spindle and cutterhead. b) knife with greatest projection determines the surface quality...................................................................................... 16

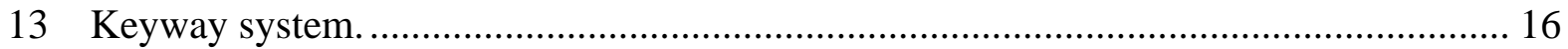

14 Clamping of a hydraulic cutterhead with high-pressure grease gun............................... 18

15 The effect of hydraulic vs. conventional tapered sleeve clamping on surface quality in a

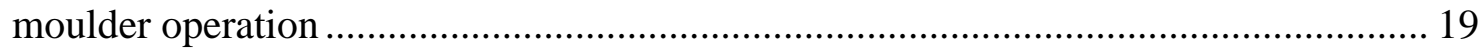

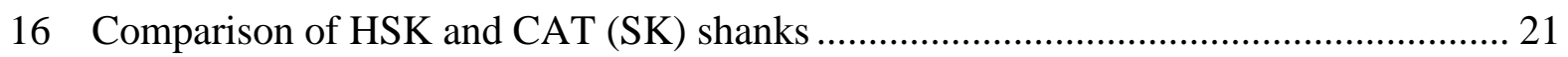

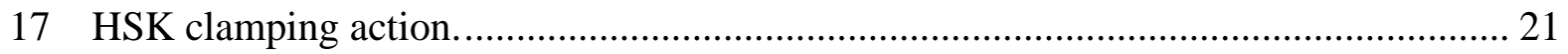

18 Powerlock clamping mechanism. ................................................................................ 22

19 Picture of conventional ISO 30 taper chuck with collet type tool gripper. ..................... 25

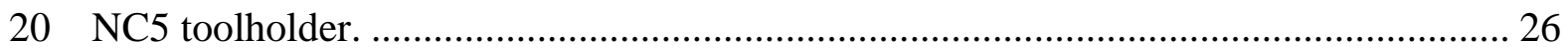

21 Axial and radial adjustment of a vertical spindle. ........................................................ 28

22 CNC spindle adjustment.................................................................................... 30 
23 Grooved bed for short, twisted and untrimmed pieces.

24 Universal spindle. 32

25 Terminology for peripheral milling. 34

26 a) up-milling, b) down-milling, c) knife path, relative to workpiece. 35

27 Surface quality relative to number of knife marks per inch (kmi). 37

28 Typical increase in power with parameter value for selected wood.

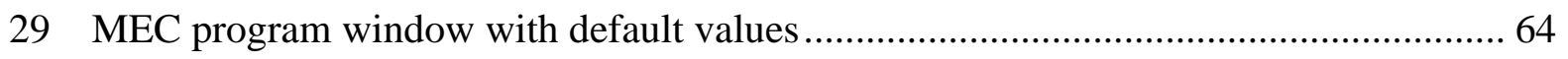

30 Effect of machine price on machining cost for different levels of production .............. 65

31 Effect of changeover time on the possible jobs or setups per shift 67

32 Effect of changeover time on production time. 68

33 Effect of machine configuration on total cost per shift. 70

34 Effect of machine configuration on machining cost. 71 


\section{Introduction}

The moulder is one of the most widely used machines in the wood industry. Prior to the introduction of the moulder concept in the 1800 's, processing a piece of wood on all four sides required the use of a jointer to face and edge the material, two passes through a planer, and if a profile was necessary, one or more passes through a spindle shaper. These steps made the process long, slow and costly. The ability to process all four sides of a piece of wood at the same time makes it cost effective to produce mouldings, flooring, door and window components, furniture and other products that we use everyday (Hassel, 2000).

Since its invention, the moulder has gone through several changes (Hassel, 2000). Machine manufacturers have developed faster moulders to produce higher volumes. They have introduced more spindles and spindle configurations for specific products and qualities. They have modified the feed system to handle shorter, out-of-square end and warped pieces. Tool clamping systems have been modified to improve precision. Safety features, such as safety hoods linked to power switches which will shut off the machine when the operator opens the hood, have been incorporated to make moulders safer machines (Derning, 1995). Moulder manufacturers are continuing to meet the dual challenge of producing more flexible and versatile machines. The major focus of Research and Development in the last years has been on quicker setup and increased productivity (Vance Publishing Company, 1992).

Today, customers demand consistent quality, smaller batches, more variety of products, shorter lead-times and customized items (Weinig P26 sales book CD). More and more people are moving toward "just-in-time manufacturing" to keep inventory down and only produce what is needed, which implies more setups in a given day. The more setups, the 
longer the time the machine is down. For example, if it takes 30 minutes to make a setup and 10 different profiles have to be produced a day, a good portion of the day will be downtime (Adams, 1992). In response, faster setup systems are being developed, such as the use of Computer Numerical Control (CNC) to adjust spindles and the recent introduction of the hollow-taper-shank (HSK) tool clamping system.

Moulders have traditionally been expected to work hard; now they are also being asked to work smarter (Vance Publishing Company, 1992). In addition to adjusting to the next required position, moulders with $\mathrm{CNC}$ controls are also capable of providing an increased amount of information to operators. Thus, the machines can generate important information to be used as a method of production management. Moulder computers can keep track of what job is being run, how many board feet are being produced, who is operating the machine and when they take breaks, helping to uncover production-related problems (Derning, 1995).

As a result, the woodworker is faced with many different machine choices that can vary greatly in price. The proper selection of features and the technical and economic impact of the selection can be intimidating. The tooling and moulder manufacturers describe the cost benefits of the new innovations of their product line. What is not always available is a clear understanding of the overall economic and productivity implications of implementing one or more of these new design features. The purpose of this project is to provide the U.S. woodworking industry with useful information on the technical and economic aspects of the modern moulder and develop an economic calculator that will help the user determine the economic impact of choosing different moulder configurations. 


\section{OBJECTIVES}

- Highlight the different technical aspects of the modern moulder: today's moulders are faster, more flexible, more versatile, more precise, safer and more productive than they were ever before. This means that the moulder features that make a moulder configuration, that is, the workpiece dimensions, the feed designs, the feed speeds, the spindle speeds, the tools, the toolholding systems, the setup systems and the options mentioned in the textbooks have changed and there is a larger collection from which to choose. In addition, there is a lot of scattered information and opinions about the machines and features that make the proper selection more confusing for the woodworker. A review and classification of the information is needed in order to provide guidance in proper selection and setup.

- Develop a simple method for assessing improvements that may occur for a particular machining operation through the acquisition of a new moulder: knowing that a particular moulder is faster or more flexible is not enough, the woodworker needs a way to quantify these advantages. The main purpose of this work is to develop an objective tool that translates the machine features into production capabilities and cost of operation. 


\section{Literature Review}

\subsection{About Moulders}

Moulders are some of the most important and widely used machines in production shops to produce large amounts of work at minimum cost. The purpose of the moulder is to cut stock that comes with rough dimensions from the rough mill to a finished width, a finished thickness and a finished cross-sectional shape in one pass (Clark et al, 1987). Figure 1 shows the cross section of different profiles that can be done with a moulder in one pass.

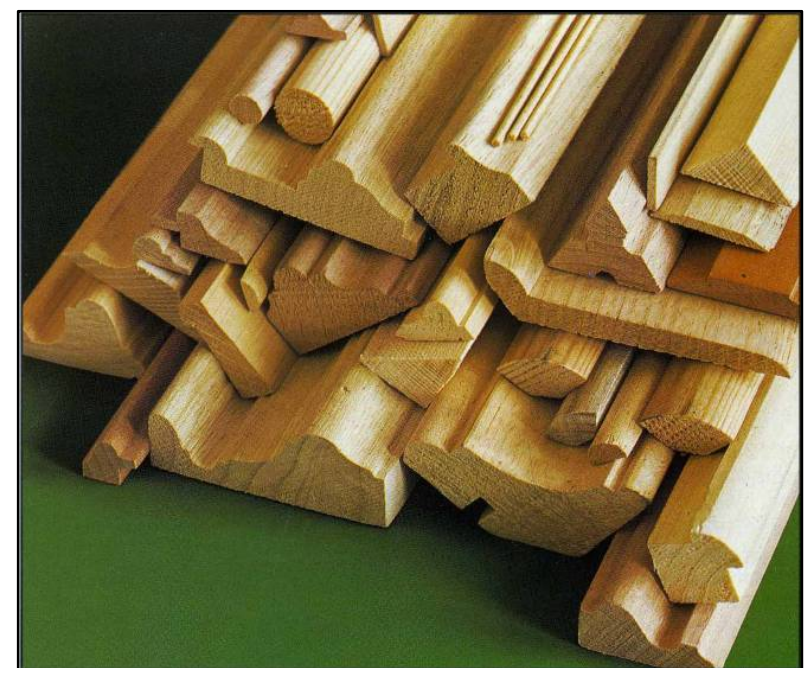

Figure 1: Different profiles made on amoulder. Source: Weinig USA brochure "Extras for Weinig automatic moulders".

A moulder consists of a heavy one-piece iron construction frame with table plates on top of it and motors that drive the spindles on which cutterheads are mounted (Weinig P26 Sales Book CD). The stock is moved through the moulder and is held in place (up against the inside fence and down against the bed of the machine) by means of feed rolls, chipbreakers and pressure bar or pressure shoes (Clark et al, 1987). These devices can be seen in Figures 2 and 3. 


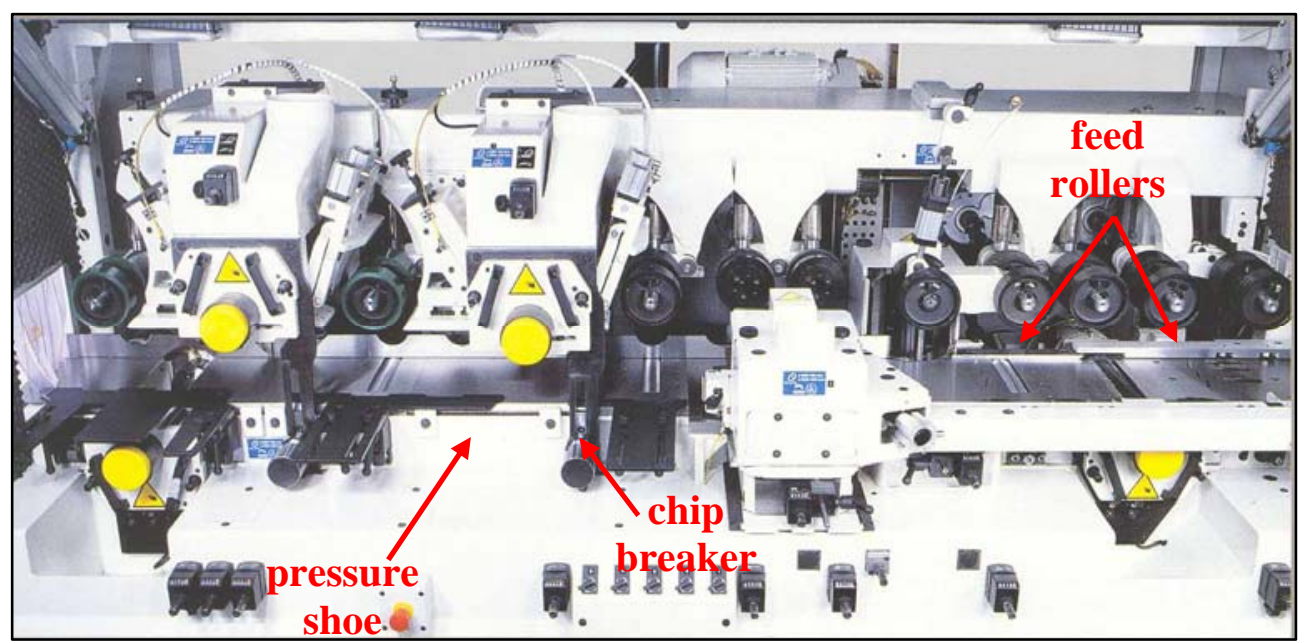

Figure 2: Devices that hold and move the workpiece through the moulder. Source: SCM brochure Compact XL.

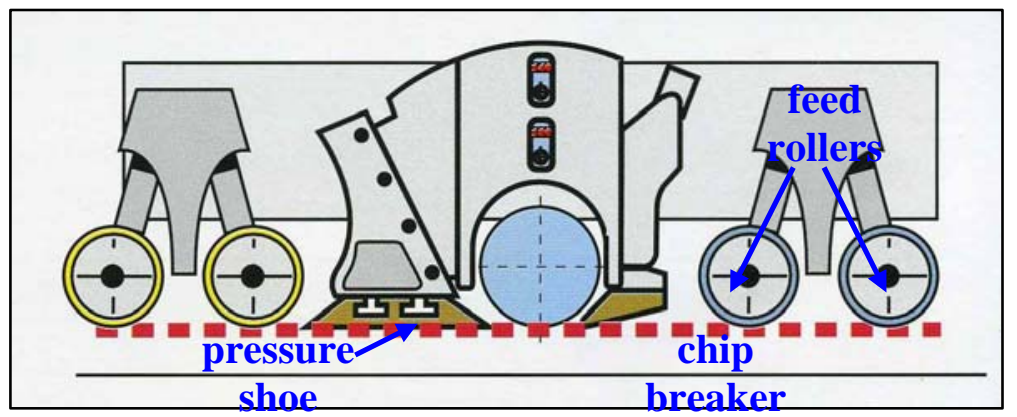

Figure 3: Side view of pressure bar and chipbreaker. Source: SCM brochure Compact XL

\subsubsection{Machine Types}

Since its introduction the moulder has gone through several changes, from "lineshaft" drive to electric motors mounted on the machine, from flat belt drive to direct drive, and then back to belt drive (Hassel, 2000). Figure 4 shows the exterior change of the moulder. 


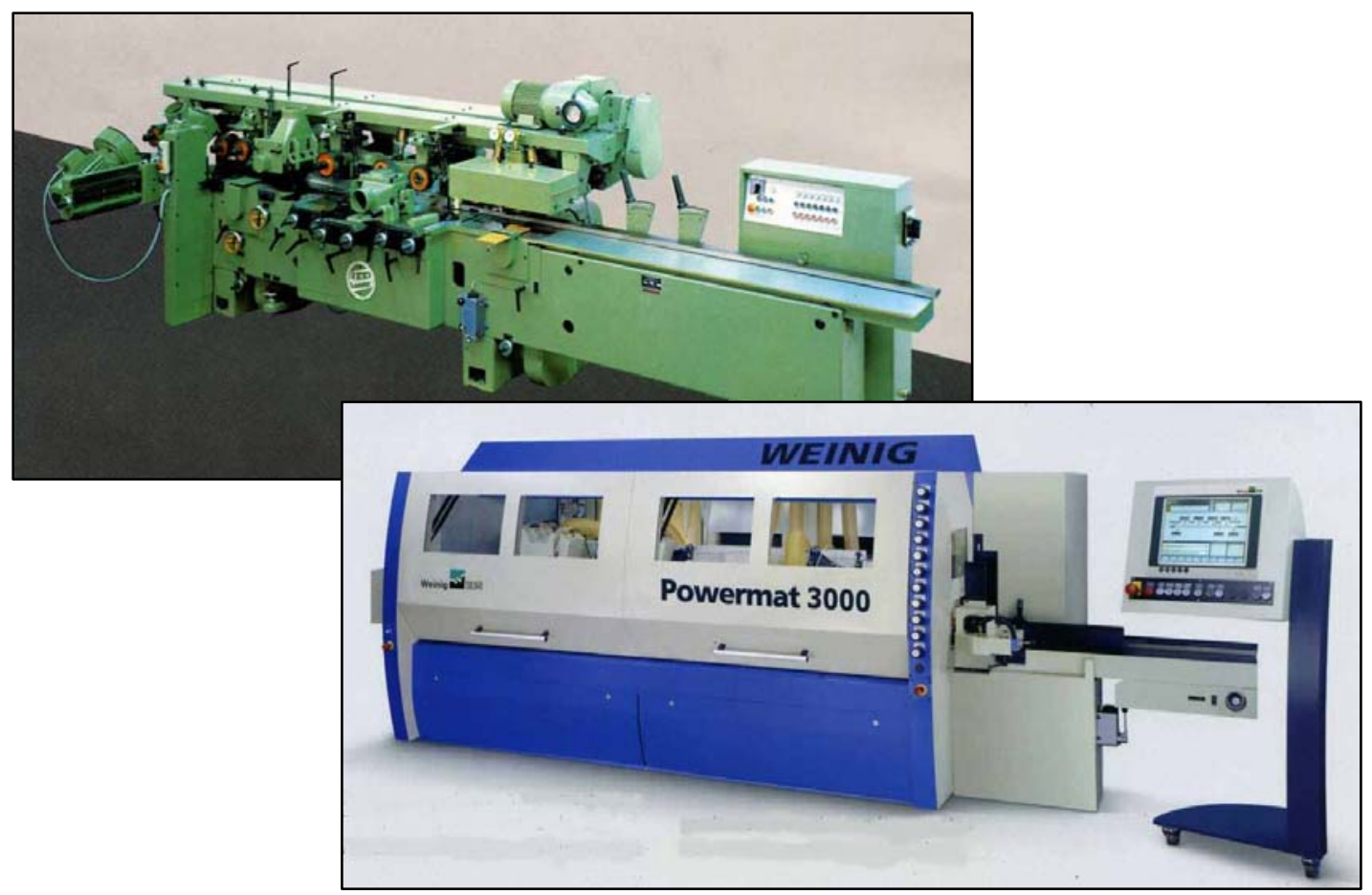

Figure 4: Picture of early moulder vs. picture of modern moulder. Source: Weinig brochures "Extras for Weinig automatic moulders" and "Powermat Series".

Today, moulder companies offer different machine types and models according to the final product and the quality the manufacturer is willing to produce. Moulders vary depending on their configuration. The machine features that determine a moulder configuration are: workpiece dimensions, spindle arrangement, feed design, feed speed, horsepower, spindle speed, tools and clamping systems, setup system and options.

\subsubsection{Machine Characteristics}

\subsubsection{Workpiece dimensions}

There are limits regarding the maximum and minimum dimensions that a moulder can cut. The working dimensions vary according to the model or size of the machine. Figure 5 illustrates the typical dimensions of the workpiece common to most moulders. Note that there 
is no maximum for length, but only for the minimum. This is because a piece needs to be held down by at least two feed rollers at a time, so that it does not jump up. The distance between the feed rollers determines the minimum machinable length. There are options and special configurations that allow the moulder to machine short pieces accurately. There are also special models and options of moulders that allow them to cut pieces of larger dimensions, for example up to $290 \mathrm{~mm}\left(11 \frac{1 / 2 ")}{}\right.$ in thickness and/or $304 \mathrm{~mm}$ (12") in width.

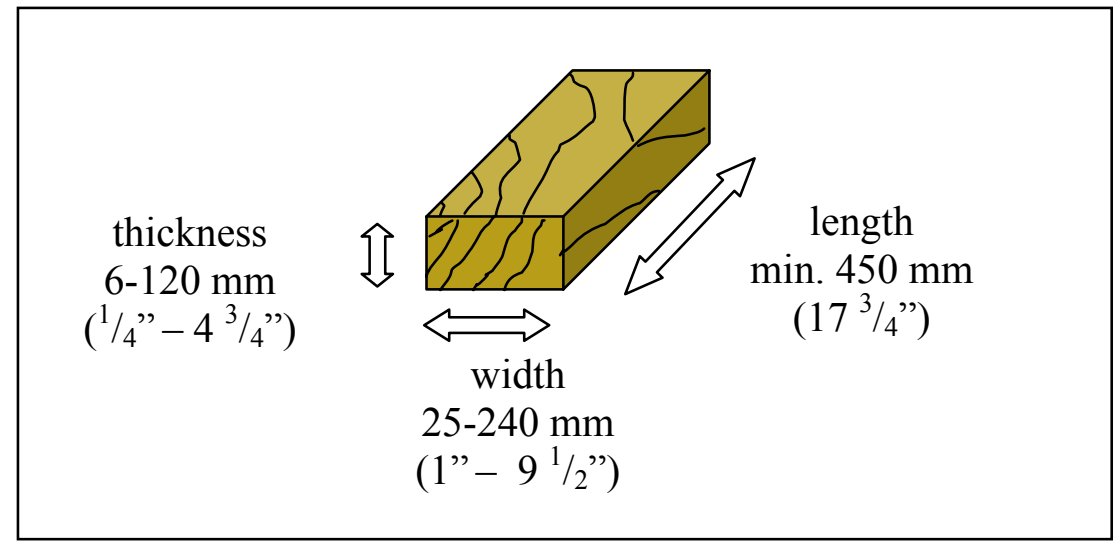

Figure 5: Working dimensions.

\subsubsection{Spindle Arrangement}

The simplest moulder has four cutterheads. The most common arrangement is: top cutterhead, outside edge, inside edge, and bottom. Most European four-head moulders are made with the bottom head on the infeed end and the top head at the outfeed. The first two cutterheads establish two reference planes on the rough stock before successive cuts are made. Subsequent moulding cuts can be accurately measured and controlled from these reference planes as shown in Figure 6. The first head on the infeed end of the machine cuts the bottom surface of the stock, as does a facer, producing a flat face that serves as a reference plane. The second head is on a vertical spindle on the right-hand side of the stock at 
90 degrees to the surface machined by the first bottom head (Clark et al, 1987). Some machines accomplish both cuts in the first spindle by means of a reference engraver. A reference engraver is a cutterhead that is combined with a planing cutterhead in the same spindle, producing both reference planes to guide the timber through the machine.

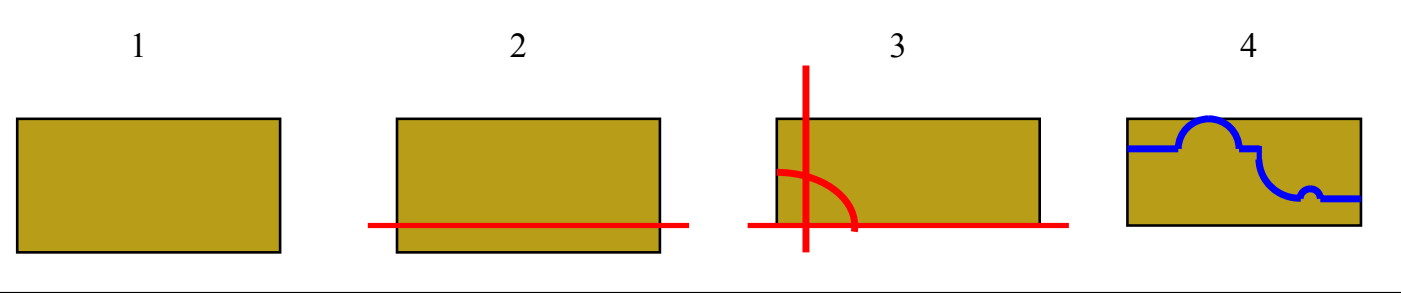

Figure 6: 1) workpiece before going through the moulder, 2) first reference plane made by first cutterhead, 3) second reference plane made by second cutterhead, 4) final profile.

Contrary to planers and matchers, where the spindles are opposite to each other, moulder sideheads are staggered to allow their spindle-mounted motors to clear each other when one of the spindles is tilted (Koch, 1985). However, for products that require a very small tolerance, such as flooring, the vertical spindles are opposite to each other (personal interview with Victor Cortes, Weinig USA, 2006).

Today's moulders are modular, meaning that the purchaser can specify a number of different spindle arrangements. The first module always consists of the facing operation with the bottom head, followed by the jointing to 90 degrees with the first vertical right-hand head. This basic sequence can then be followed by additional spindles (Clark et al, 1987). Additional spindles are added to help remove more material with lower load on each motor (personal interview with Victor Cortes, Weinig USA, 2006). The right arrangement depends on the product and quality that the manufacturer wants to produce (personal correspondence 
with Dr. Johannes Tröger, Stuttgart University, 2006). Figure 7 portraits some examples of spindle arrangements:

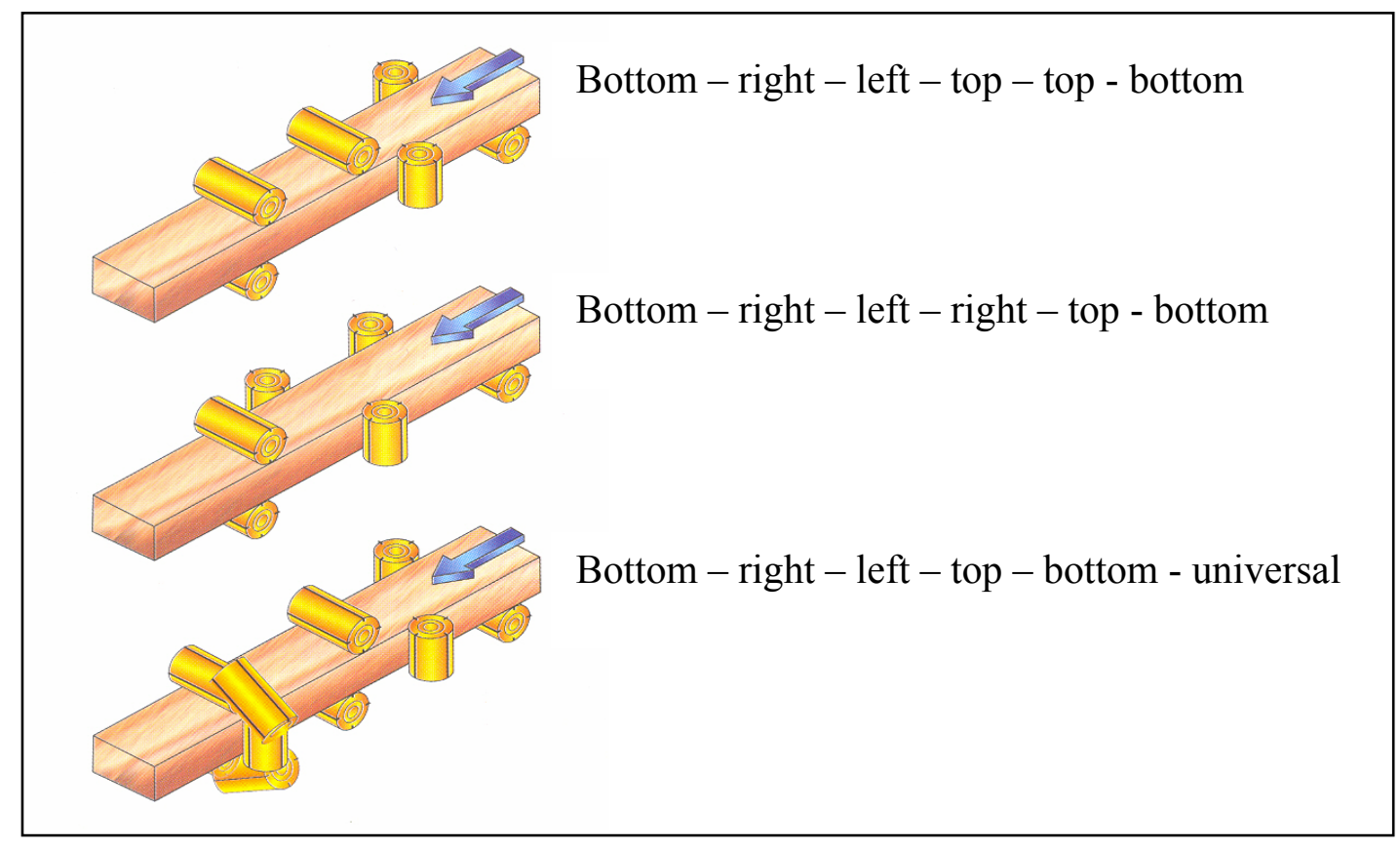

Figure 7: Examples of spindle configurations. Source: SK Machinery brochure.

\subsubsection{Feed Design}

Until 1969 all moulders were the pushfeed type (Hassell, 2000). Pushfeed type moulders have a stationary bed with only infeed rolls, so that the pieces of wood push each other through and out of the machine. A pressure bar that extends after the first head to the back end of the machine is needed to hold the stock firmly down on the bed for all cutterheads (Clark et al, 1987).

In the feed-through modular-design or feed-through moulder, individual pieces of stock are fed through the machine by powered feed rolls, which are located both before and after each of the cutting heads. This concept brought about the following advantages: 
- Since each piece of stock can go completely through the machine without being pushed by the piece behind, losses due to cutterhead burn marks caused by the hesitation or stopping of the push feed are prevented. In addition, the last piece automatically clears the machine, and there is less waste of material during set-up adjustments (Clark et al, 1987).

- The long infeed table and the top-mounted infeed rolls make it possible to straighten and face the bottom of the stock and joint the right-hand edge. Straightening is not possible on a push-feed moulder (Clark et al, 1987).

- A large number of heads can be specified without loosing traction, because each additional head has its own power-feed rollers (Clark et al, 1987).

- Less set-up time is required because the long pressure bar is not required (Clark et al, 1987).

\subsubsection{Feed Rate}

The feed rate is the speed at which the workpieces are run through the machine. The average feed speed offered by most machine manufacturers is $5-24 \mathrm{~m} / \mathrm{min}(16-80 \mathrm{ft} / \mathrm{min})$, with possibility of increasing to about $36 \mathrm{~m} / \mathrm{min}(120 \mathrm{ft} / \mathrm{min})$. Today, high speed moulders can achieve maximum feed speeds between $60 \mathrm{~m} / \mathrm{min}(196 \mathrm{ft} / \mathrm{min})$ and $600 \mathrm{~m} / \mathrm{min}(1970$ $\mathrm{ft} / \mathrm{min})$.

\subsubsection{Spindle speeds}

Moulders use belt-drive (flat belt and cogged belt) with three-phase asynchronous (AC) motors in the power range of 5 to $50 \mathrm{hp}$. Inverters can be used on the feed system to 
control feed speed at the turn of a dial. Depending on the belt drive transmission and the engine speed ( $3000 \mathrm{rpm}$ at $50 \mathrm{~Hz}$ and $3600 \mathrm{rpm}$ at $60 \mathrm{~Hz}$ ), different revolutions for the spindles can result, from 6000 to 12,000 rpm (personal correspondence with Hubert Klein Michael Weinig AG and Bob Koenigsfeld - SK USA, Inc.).

Spindle rpm is adjusted by changing the pulley on the motor and/or the spindle (personal correspondence with Hubert Klein - Michael Weinig AG and Bob Koenigsfeld SK USA, Inc.). Koch (1985) reported that the controls of many machines were so designed that synchronous spindle speeds could be selected at 3,600,6,000 or 7,200. Today machine manufacturers offer standard 6,000 rpm spindles and some have moulders with spindles that run at 8,000 and $8,300 \mathrm{rpm}$. The recent adoption of the HSK tool holding system allows up to $12,000 \mathrm{rpm}$.

\subsubsection{Tools and Clamping Systems}

\subsection{Tools}

The tools used in moulders are called cutterheads. Cutterheads differ in tool design and function. The tool design refers to whether the tool is a one-part regrindable tool, has tipped knives or loose knives and how these knives are attached to the cutterhead. The knife clamping can be mechanical or centrifugal. The knives can be regrindable, reversible or exchangeable. Some knives can be both reversible and regrindable. According to their function, there are planing cutterheads and profiling cutterheads. There are planing cutterheads that can have inserts that allow beveling, rounding or profiling at the same time. Profiling cutterheads can: 
- Be only for a specific profile such as grooves, tongue and grooves and profile/counter-profiles.

- Have a profile that can be used for multiple-purposes by using different parts of the cutterhead or by combining cutterheads.

- Have blank knives that can be profiled as desired by the user using a template.

- Use different standard profiled knives. This cutterheads are called universal cutters and the number and choice of profiles vary from one tool manufacturer to another (Effner, 1992).

For special applications, circular saw blades can also be mounted on a spindle.

More detailed descriptions of tools are found in the book "Chisels on a Wheel" by Jim Effner and in the book "Furniture Manufacturing Equipment" by Edward L. Clark, et al. Catalogs from the major tool manufacturers such as the Leitz Lexikon also offer good technical explanations of the various tools.

\subsection{Clamping systems}

Clamping systems are the means to hold and drive the cutterheads with motors or machine spindles (Effner, 1992). Reducing static runout has been the main objective of tool centering and clamping techniques (Stewart, 1990). Static runout can be defined as the total linear displacement of the path of rotation of the tool from the axis of rotation as measured by a dial indicator as the tool is slowly rotated (Wowk, 2000). Dynamic runout is the result of the non rigid behavior of rotor systems in which the magnitude of the runout changes when the rotor changes shape as rotational speed is increased (Wowk, 1994). Possible causes of static runout include shaft/bearing alignment issues, a bent or otherwise distorted shaft, 
inaccurate tool mounting, and tool concentricity errors. For most wood working tools radial runout has the greatest impact on the final surface quality of the product. When considering circular saws the axial runout is usually the most important consideration, however, radial runout can cause vibration, which excites axial runout (Stewart, 1990). Figure 8 illustrates the radial runout of a cutterhead and axial runout of a circular saw.

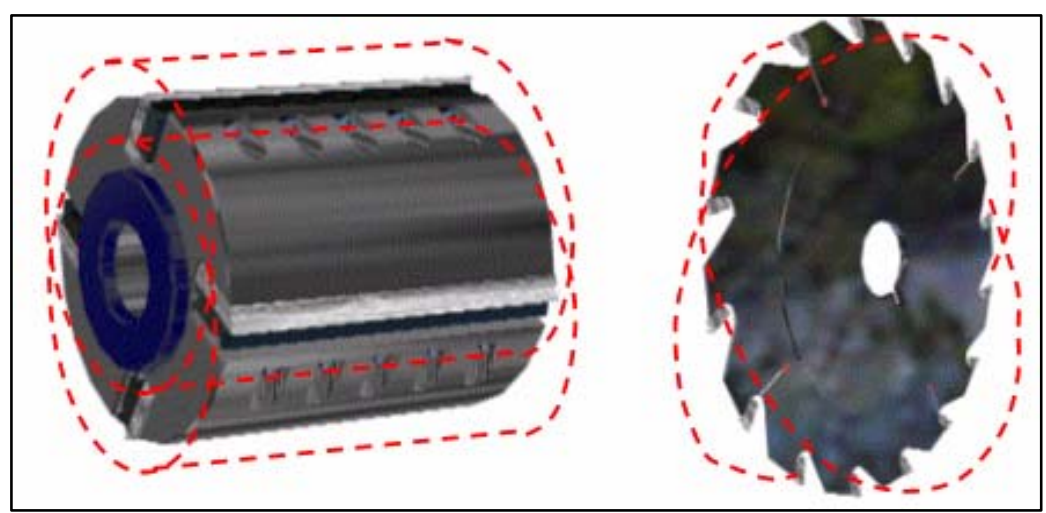

Figure 8: Radial static runout condition for a cutterhead (left) and axial static runout condition for a circular saw blade (right). The path traced by the cutting tool is indicated by the dashed line (Horn, 2004).

\subsection{Jointing}

Poor static concentricity of the cutting knives of a cutterhead usually results in uneven knife marks or a single knife finish. To remedy this, the knives on the cutterhead are sometimes honed in a process called jointing. Jointing helps ensure that all of the knives are on the same cutting circle. This is done, by passing a hone over the knives, while the cutterhead is rotating at operational or slower speed as seen in Figure 9. The jointing process results in a small area on the tip of the knife, known as the "joint land" at which the clearance angle of the knife is zero (see Figure 10). Jointing in cases where static runout has been caused by inaccurate grinding, poor cutterhead centering, defective bearings etc. will result in 
an uneven joint land width that will cause uneven tool wear and a reduction in the quality of surface produced due to irregular knife heel marks (Stewart, 1990).

Jointed moulders are generally regarded as a popular choice for companies looking for a moulder with high feed speeds for high production. The drawbacks are that they are more expensive and that they require more time for setup changes and a higher skill level from the operator (Derning, 1995).

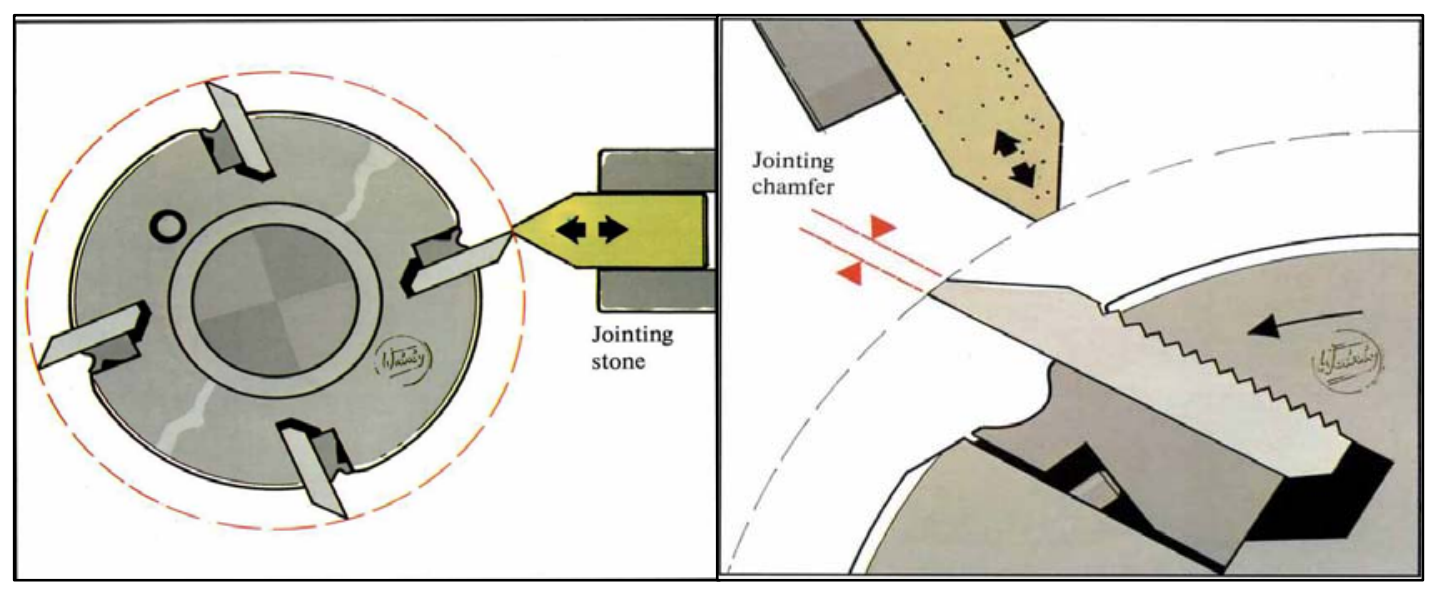

Figure 9: a) Knives honed with jointing stone to the same cutting circle. b) Jointing chamfer or joint land on the knife as a result from jointing. Source: Weinig brochure "All about tools".

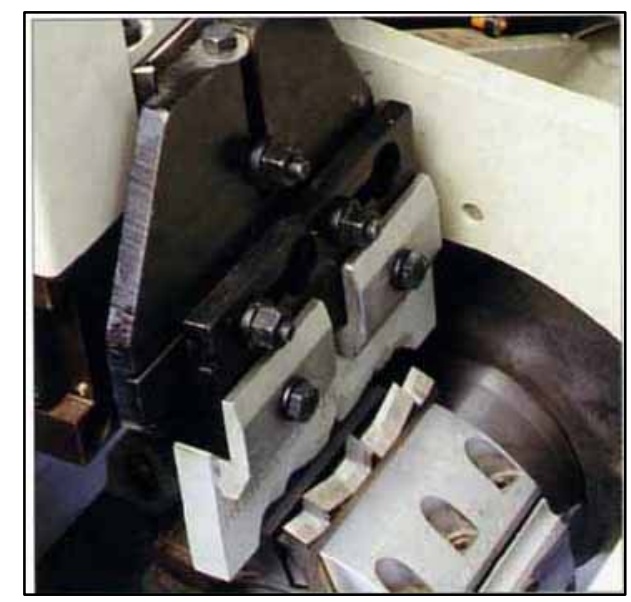

Figure 10: Profiled jointer in moulder. Source: Weinig brochure "Powermat Series". 


\subsection{Self-Centering and Clamping System}

The self-centering and clamping system was one of the first attempts to correct eccentricity between cutterheads and spindles. It consists of a set of tapered collars, similar to those used to hold and drive router tools, but larger. The inside of the collars are straight, parallel, and the same size as the spindle they are placed on. The tool body is machined to mate exactly with the taper of the collars. Tightening the retaining nut on the sleeve compresses the collars to grasp the spindle and force them against the tapered inner walls of the cutter body (see Figure 11). The problems associated with this system are that the movable parts wear out, they are affected by dirt and dust and they are time consuming to use (Effner, 1992).

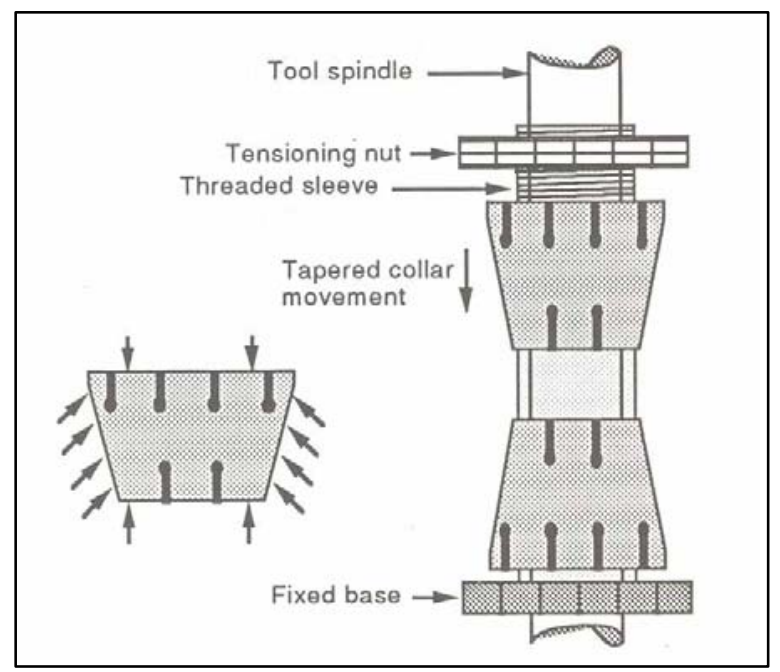

Figure 11: Self-centering and clamping system. Source: Effner, 1992.

Since the hole of the cutterhead is larger than the diameter of the straight spindle and there must be a slip fit between the collars and the spindle (see Figure 12 a), the quality of the surface finish is not very good (Clark et al, 1987). This tolerance can be up to $0.05 \mathrm{~mm}$ 
(0.002") and can cause the tool to run eccentrically on the spindle. The result is that although all the cutters are cutting, only the cutting knife with the greatest projection determines the quality of the surface (Weinig USA). This is what is known as a "one-knife-finish" as shown in Figure 12 b.

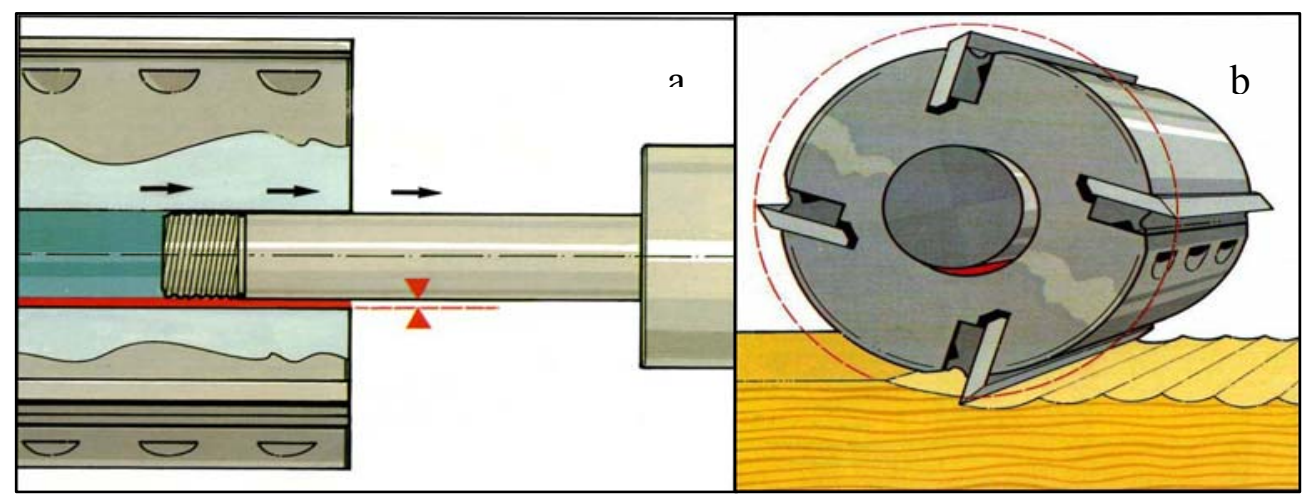

Figure 12: a) Fit tolerance between spindle and cutterhead. b) Knife with greatest projection determines the surface quality. Source: Weinig brochure "All about tools".

\subsection{Keyway System}

Figure 13 illustrates how the keys and keyways are used to connect spindles and tools. This system was developed to solve at least two problems of more recent machine and tool technology:

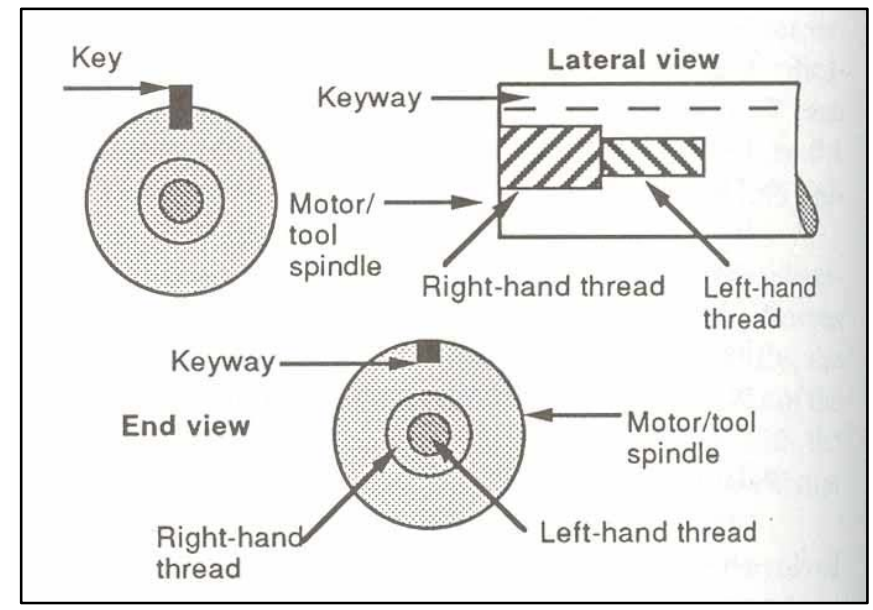

Figure 13: Keyway system (Source: Effner, 1992) 
- Help transmit greater horsepower to the cutting tool and provide a safety measure when the tool strikes a solid object, because the key will shear off, protecting the machine and the machine operator (Effner, 1992).

- With the shaft internally threaded with both left- and right-hand configurations, the rotation can be reversed simply by changing the retaining bolt, providing the ability to either climb cut or abrasive cut, a considerable benefit (Effner, 1992).

Although this system is still used, it has a number of known disadvantages (Samelius, 1990):

- The keyway reduces the strength of the shaft.

- The stress at the bottom of the keyway can cause rupture.

- Even when properly manufactured, backlash is usually present and gets worse in operation. Fretting corrosion occurs.

- The joint cannot be adjusted when mounting.

- Difficulties when dismantling.

- "Hidden" costs for design, manufacturing and mounting (Samelius, 1990).

In order to eliminate the keyway joint and its disadvantages, so called friction joints have been developed, to provide a rigid joint. Friction joints can be either mechanical or hydraulic (Samelius, 1990).

\subsection{Hydro}

Hydraulic tool holding systems have been successfully used in different woodworking machines such as moulders, planers, circular saws as well as $\mathrm{CNC}$ routers 
(Samelius, 1990). A hydraulic tool holding system works by pressurizing a thin double walled sleeve with enclosed hydraulic fluid. Because of the even pressure distribution of the fluid in the sleeve, the system provides a very accurate method of tool clamping and centering (Ponsolle, 2004). Figure 14 is a diagram of a hydraulic tool holding system.

When looking at hydraulic devices for centering and fastening of tools in moulders there are two systems (Samelius, 1990):

- Integrated system used for cutterheads. In this system, pressurizing (fastening) is done with a grease pump (Samelius, 1990).

- Separated systems. The clamping device is a separate sleeve unit. There is the possibility to move from one tool to another. Pressurizing can be done with a grease pump or a screw (Samelius, 1990).

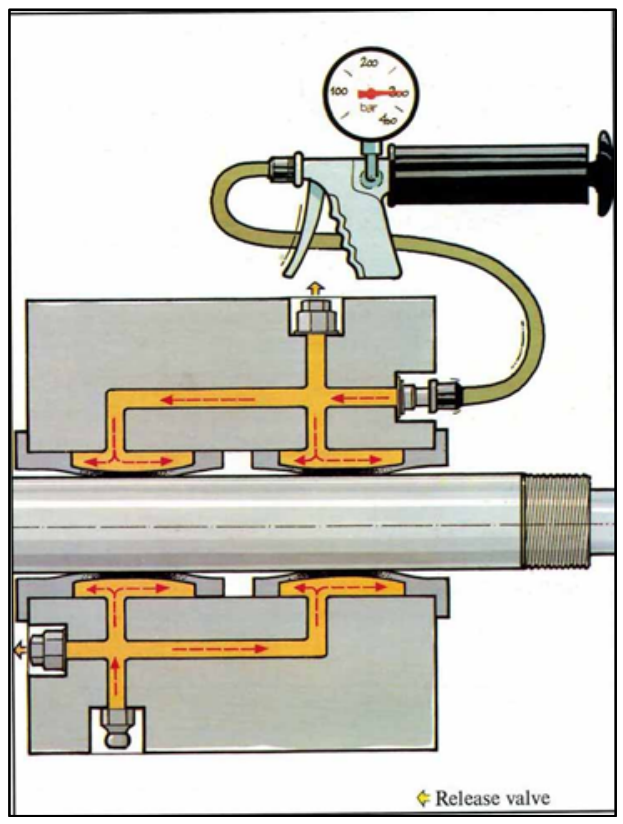

Figure 14: Clamping of a hydraulic cutterhead with highpressure grease gun. Source: Weinig brochure "All about tools". 
The accurate centering capabilities of a hydraulic tool holding system also allow cutterhead knives to be ground to closer tolerances if hydraulic clamping of the cutterhead is also used at the grinding operation (Samelius, 1990). This reduces the need to joint the cutterheads and the amount of jointing necessary, and with sharper knives (recalling that jointing is a dulling process), a much better final surface can be produced. Figure 15 shows an example of the ideal effect on surface quality when using hydraulic clamping versus conventional tapered sleeve clamping in a moulder operation (as presented by ETP Transmission). It is quick and easy to get good runouts in the range of $0.002-0.005 \mathrm{~mm}$ $(79 / 1,000,000 "-2 / 10,000 ”)$. However, there is a higher cost and regular maintenance is necessary to avoid the seals from developing leaks that make the tools slip (Destefani, 2002).

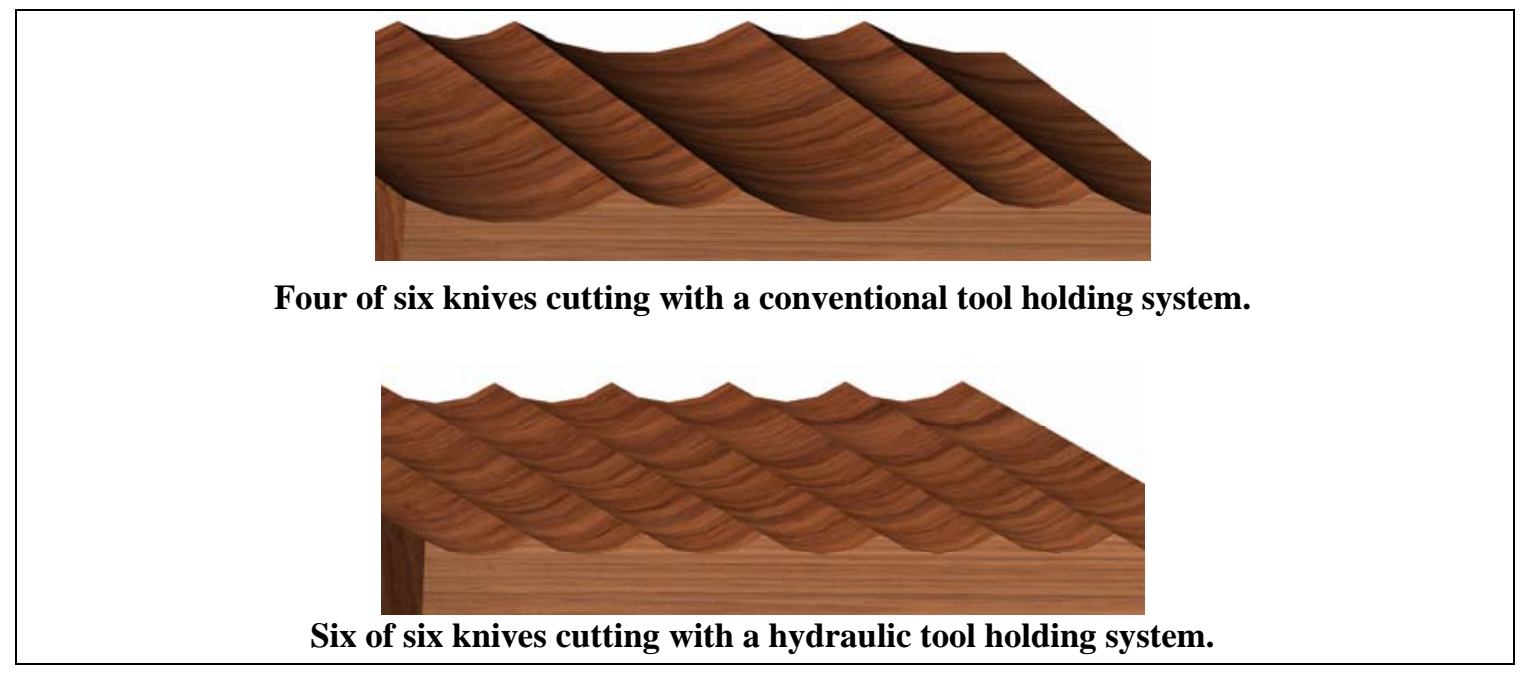

Figure 15: The effect of hydraulic vs. conventional tapered sleeve clamping on surface quality in a moulder operation. Picture courtesy of ETP Transmission. 


\subsection{HSK}

The most discussed toolholding system today is HSK (Lewis, 1999). It stands for "hollow-taper-shank" as translated from German (Kocherovsky and Travis, 1998). HSK was developed as a response to the demand from the industry for a common tool interface for various machines, since there were many modular tooling systems which all claimed to be the best (like ISO and BT) and because traditional steep tapered shanks also slowed the growth of high speed applications (Kocherovsky and Travis, 1998). HSK has been widely used in the metalworking industry and was first introduced in the woodworking industry for $\mathrm{CNC}$ routers. At the $5^{\text {th }}$ Industrial Symposium on Tooling \& Machining for the Wood Industry in 2000 , the potential and advantages of using HSK in moulders was already being discussed. Recently one of the leading moulder manufacturers has launched a whole line of moulders with HSK.

An HSK connection depends on a combination of axial clamping forces and tapershank interference (Kocherovsky and Travis, 1998). The back of the V-Flange contacts the face of the spindle at the same time the tapered shank makes full contact with the tapered spindle socket. This two-point contact with the spindle is critical in high speed machining applications. Conventional steep-tapered toolholders contact the spindle only on the tapered shank (Albert, 2000). An HSK shank has a ratio of 1:10, compared to CAT (BT, SK) shanks that have ratios of 7:24 Regarding accuracy and resistance to tool runout, the HSK interface is equivalent to CAT (SK, BT) in radial accuracy, with runouts of $0.10 \mathrm{~mm}$ (0.004 in), while providing significantly better axial accuracy (Kocherovsky, 2001). CAT and BT shanks are explained in section 3.1.2.6.4. Figure 14 compares a HSK shank with a CAT shank. 


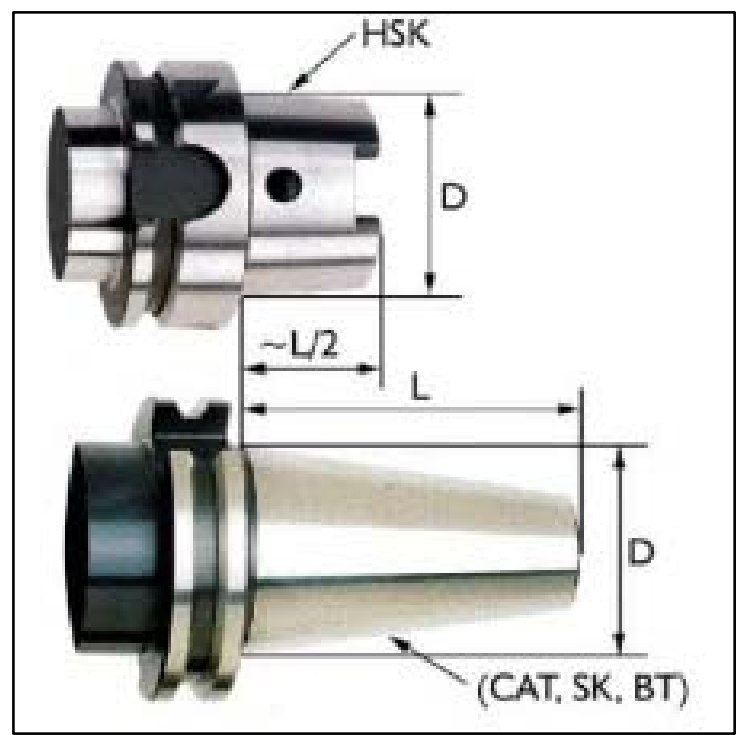

Figure 16: Comparison of HSK and CAT (SK) shanks. Source: "HSK: Characteristics and Capabilities" by E. Kocherovsky

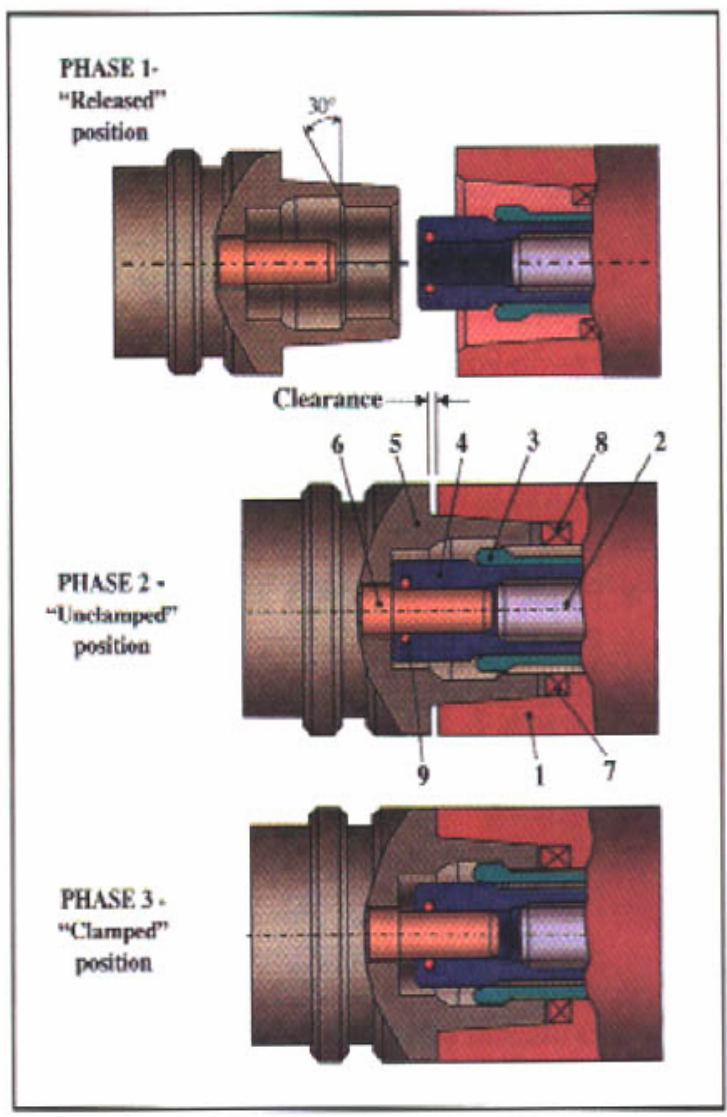

Figure 17: HSK clamping action. Source: Kocherovsky and Travis, 1998. 
The difference between the standard HSK and the HSK used in moulders is the size of the flange. The flange face is about $25 \%$ larger for more surface area for axial and radial rigidity. This allows the use of the larger moulder cutterheads, which weight about $13.6 \mathrm{~kg}$ (30 lbs), at 12,000 RPM (personal correspondence with Tim Finger, Great Lakes Custom Tool, Mfg. Inc.). Figures 17 and 18 illustrate the phases of the clamping mechanism.

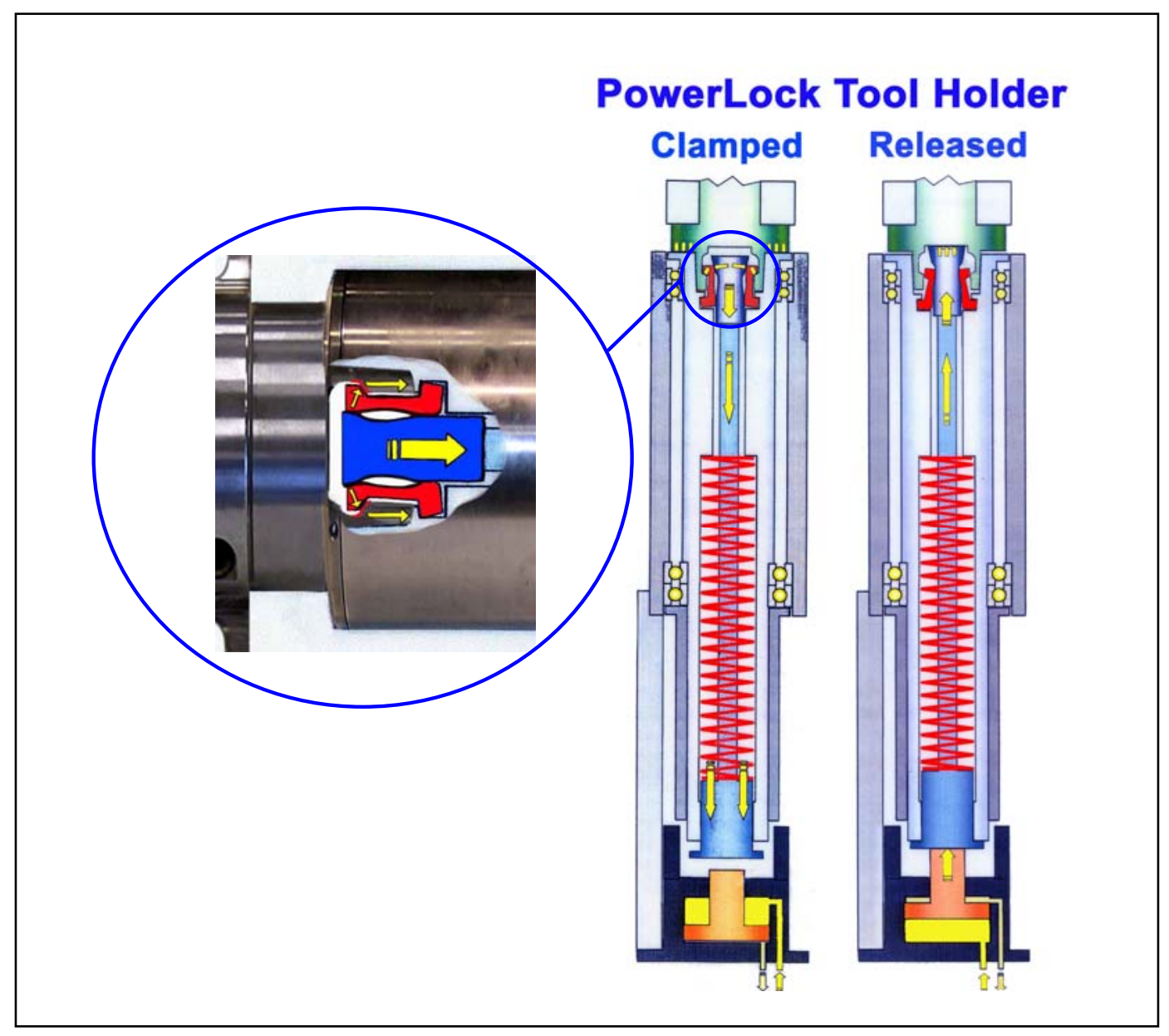

Figure 18: PowerLock clamping mechanism. Source: Weinig, USA.

The toolholder's rotation has a beneficial effect on the holding power of the mechanism. Since HSK holds the tool from the inside out, the design actually utilizes 
centrifugal forces to increase joint strength. As the collet segments rotate, the clamping mechanism gains centrifugal force (Kocherovsky and Travis, 1998).

Centrifugal force also causes the relatively thin walls of the tapered shank to deflect radially at a faster rate than the wall of the spindle. This leads to a secure connection by assuring strong contact between the shank and the spindle. The changes caused by the centrifugal force on the inside of the clamping mechanism won't affect the axial position of the cutting edge, because this is determined by the face-to-face contact between the flange and the receiver (Kocherovsky and Travis, 1998).

Additional advantages of the HSK system as listed by Kocherovsky and Travis are:

- Highest tool changing and repeating accuracy

- Lower tool runout

- Lower tool change stroke and time

- Suitable for different cutting conditions

- Lower weight than most tool holders

- Lower load for the spindle bearing

- Universal use: turning, milling, grinding, etc.

- Adapted for manual and automatic handling

- Adapted for balancing

- Incorporates internal coolant supply

- Multiple vendor source, competitive pricing, stock items

- Modular systems available (extensions, reducers) 


\subsection{Other clamping systems}

There are clamping systems that are not used in moulders at the moment, but are used in CNC-routers. Since that was the case with HSK until recently, it was considered important to mention them in this paper.

Many CNC router spindles employ tool changer type chucks which consist of a cone shaped portion of the chuck that is held in place in a corresponding taper inside the nose of the spindle by a power draw bar and retention knob system. The chuck system shown in Figure 19 allows automatic tool changers to be utilized to remove a tool/chuck assembly and replace it with a different tool chuck assembly as part of the machining process (Annamalai, 2003). There are multiple different standard tapers, each differing in (a) the diameter at the small end of the truncated cone (minor diameter); (b) the diameter at the large end of the truncated cone (major diameter); (c) the axial distance between the two ends of the truncated cone (Wikipedia, 2006). The spindle- chuck interfaces commonly available include ISO, CAT, BT and HSK connections (Annamalai, 2003). ISO is named after the International Organization for Standardization, CAT was developed by Caterpillar and is governed by the American National Standards Institute (ANSI) standard and BT is mostly used in Japan and Europe. The larger the number behind the CAT or BT, the larger the holder is. For example, BT30 is considered a small, light tooldholder, and CAT60 a very large and heavy toolholder (Baier, 2006). The tapered cones (ISO, CAT and BT) used in wood machining are typically in the BT 30 to 35 size range and have relatively low torque transmission capability which worsens when damaged or improperly maintained and/or are dirty. At high spindle speeds, the spindle expands and the taper moves into the spindle further, altering the axial location of 
the tool. For high cutting forces, the radial location accuracy is inadequate, because the interface's design tolerances allow a clearance at the back of the connection (Annamalai, 2003).

In $\mathrm{CNC}$ routers, tool changer type chucks must also incorporate a system for holding the tool in the chuck. Typical tool gripping systems found in the woodworking industry are the collet type systems, which have limited torque transmission capabilities, and generally produce relatively high tool runout for high-speed operation. Other shank holding systems available include collets, conventional hydraulic and hydro-mechanical systems, heat shrink systems (Annamalai, 2003) and the Tribos ${ }^{\circledR}$ system. This is different for moulders, where the tools are directly mounted on the spindle as with conventional and hydraulic systems, or where the chuck is part of the tool as in HSK.

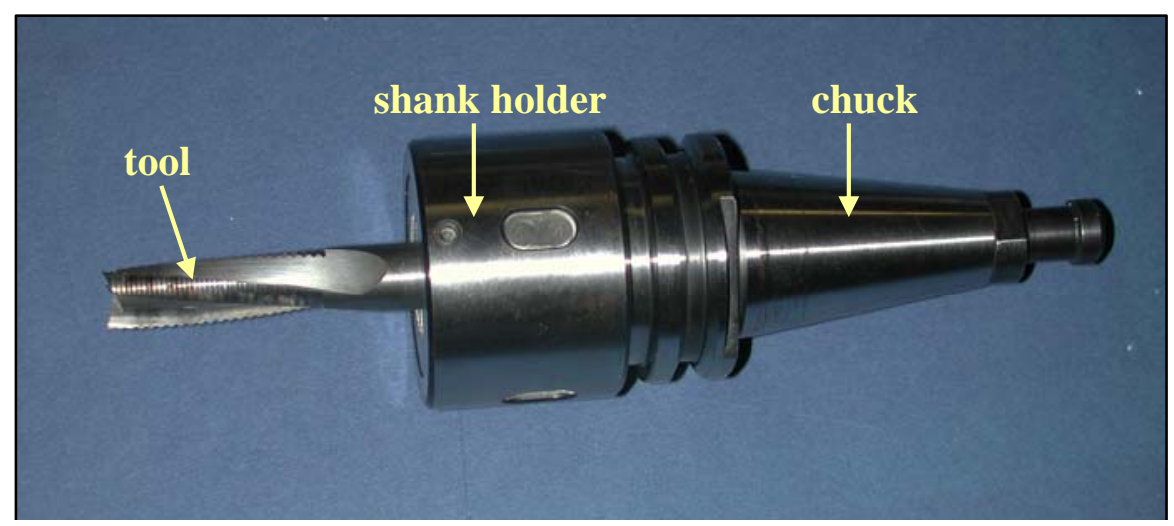

Figure 19: Picture of conventional ISO 30 taper chuck with collet type tool gripper.

NC5 is a new toolholder design that has been developed by Nikken Kosakusho Works, Ltd. of Osaka, Japan as an alternative to HSK. Like the HSK toolholder, it has a shallow taper and features two-point contact with the spindle. NC5 differs from HSK in how holder-to-spindle contact is achieved. The shank of the toolholder of the NC5 consists of two 
parts: a solid cylindrical core inside a cone-shaped shell. This shell is split. A diagonal slit running up and down the taper can be seen in Figure 20. The shell, though split, is preloaded against the V-flange with a Belleville disc spring. When the spindle drawbar pulls the toolholder into the spindle socket, the tapered cone makes contact with the tapered surface of the socket. Because the shell is slit, it can yield a little, contracting slightly to conform to the socket. This action makes complete contact between mating surfaces yet allows the tool to be centered very precisely. As the toolholder is pulled further into the spindle, the springs between the shell and flange are compressed until the rear of the flange butts up against the face of the spindle. Because the action absorbs slight gage line error, near-perfect two-point contact is achieved even in cases where the spindle has experienced some wear or has been reground (Albert, 2000).

The split shell has another critical function. As the spindle opens at high speed, the Belleville disc spring pushes the split shell upward, thus maintaining the full contact with both taper and flange, its developers say (Albert, 2000).

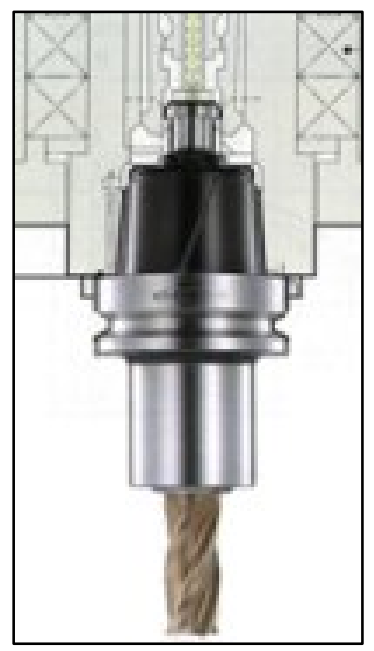

Figure 20: NC5 toolholder. Source: Modern Machine Shop, 2000. 
Apparently, this approach has several advantages over the hollow taper. Even though an HSK toolholder is hollow, the clamping mechanism inside leaves no room for the shank of the cutting tool, whereas the NC5 allows the cutting tool's shank to be inserted deeper, reducing overall length. Its developers also say that the mass of the solid shank provides more vibration damping. The slit in the tapered shell and the spring action on the flange also keep vibration down. In addition, the solid construction should resist breakage in case of an accidental collision (Albert, 2000).

HSK has been a major development in response to the extraordinary forces encountered in high speed applications. But new insights and further innovation can be expected and new alternatives should be examined (Albert, 2000).

\subsubsection{Set-up}

Set-up can be explained as the preparation of the moulder for the next production run (Hassell, 2000), and generally includes:

- Removing the tooling used on the previous profile.

- Installing the tooling required to produce the next profile.

- Making all the necessary adjustments with regard to the cutterheads, feed rollers, bedplates, fences, chip-breakers and pad pressures, etc.

- Carry out the jointing process if there are no automatic jointers (Hassell, 2000).

The adjustment of the cutterheads is the axial and radial positioning of the spindle as seen in Figure 21 to achieve a desired width with a vertical spindle and a desired thickness with a horizontal spindle. Chip-breakers and pressure shoes also need to be adjusted for the upper horizontal spindles and right vertical spindles. 


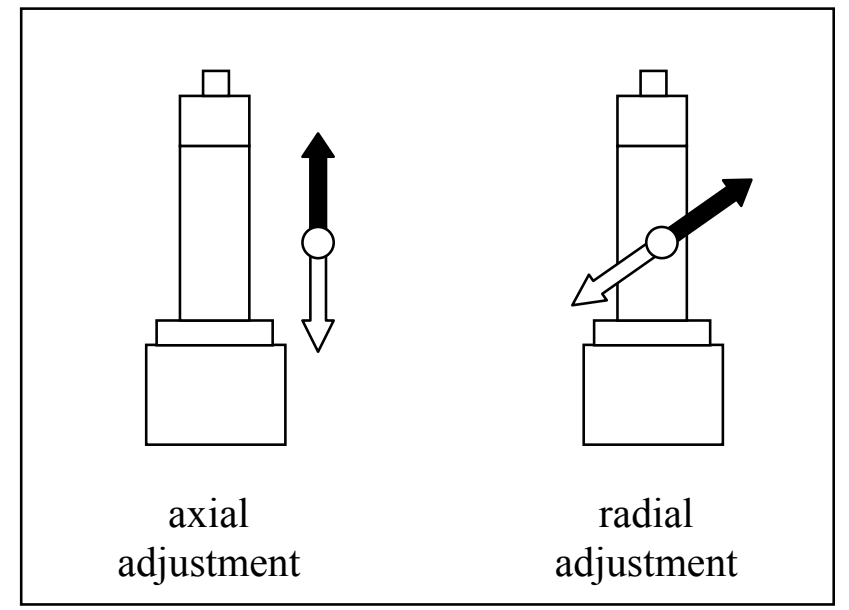

Figure 21: Axial and radial adjustment of a vertical spindle.

When using older type moulders, which generally are not fitted with the mechanical or electronic spindle position indicators, up to $50 \%$ of the total set-up time can be accounted for by the operator having to "guess" the position of the tooling to produce the required profile (Hassell, 2000).

For the radial adjustment with mechanical spindle positioning indicators, the operator needs to know the radius (r) of the tool and the desired width/thickness of the stock (d). The sum of these values $r+d$ tells the operator where to position the spindle. The absolute position of the spindle (from the center line of the axis) to the reference point is displayed in the mechanical readout. This reference point or zero is the fence for vertical spindles and the table or bed plate for horizontal spindles. The operator cranks the positioning wheel/handle to meet the calculated value that will give him the desired width/thickness. Also available on some equipment are counters that have a flip lever built in that allows the operator to plug in the same the values of $r$ and $d$ in two different windows on the same counter, so there is no 
need for a calculation by the operator (personal correspondence with Shawn Pogue, Weinig USA).

For the axial adjustment, the operator needs to know the distance between the shoulder of the spindle on which the cutterhead is mounted and a reference point in the profile and on the knife. Alternatively, the operator can use set-up parts or reference pieces to do the setup, but this means having one for every different profile produced and will only get you as close as the last run which would force the operator into making sure that these samples are kept at a constant moisture content to avoid changes in dimensions due to shrinkage or swelling. However, if choosing this "sample" route, one should always write the required values on the sample due to dimensional shifts in the sample (personal correspondence with Shawn Pogue, Weinig USA).

With electronic spindle position indicators the operator still needs to know the radius of the tool and the desired width/thickness but the readout gives the operator a prompt to reach and tells him in which direction to crank the wheel/handle to position the spindle. The use of electronic digital readouts has made moulder setup easier, more productive, more affordable and accurate (Derning, 1995). Electronic digital readouts offer convenience and efficiency in machine setup without the additional expense of CNC (computer numerical controls). This makes the machines more affordable, and easier to learn to operate. Not only can changeover time be as little as three or four minutes, but running sample pieces through the machine to check for accuracy is no longer necessary (Derning, 1995).

CNC takes the guessing out of moulder setup and greatly reduces the time required between profile changes, meets exacting tolerances and offers production information. Like 
electronic readouts, $\mathrm{CNC}$ can also eliminate the running of scrap pieces through the machine to get the correct measurements. It is only necessary to punch in the next profile and the machine will automatically adjust to the next setting telling the operator which tools to use. Figure 22 illustrates spindle positioning using $\mathrm{CNC}$. In addition, the information generated can be used for production management. Additionally some moulder computers can keep track of what job is being run, how many board feet are being produced, even who is operating the machine and when they take breaks, information that can help uncover production-related problems (Derning, 1995).

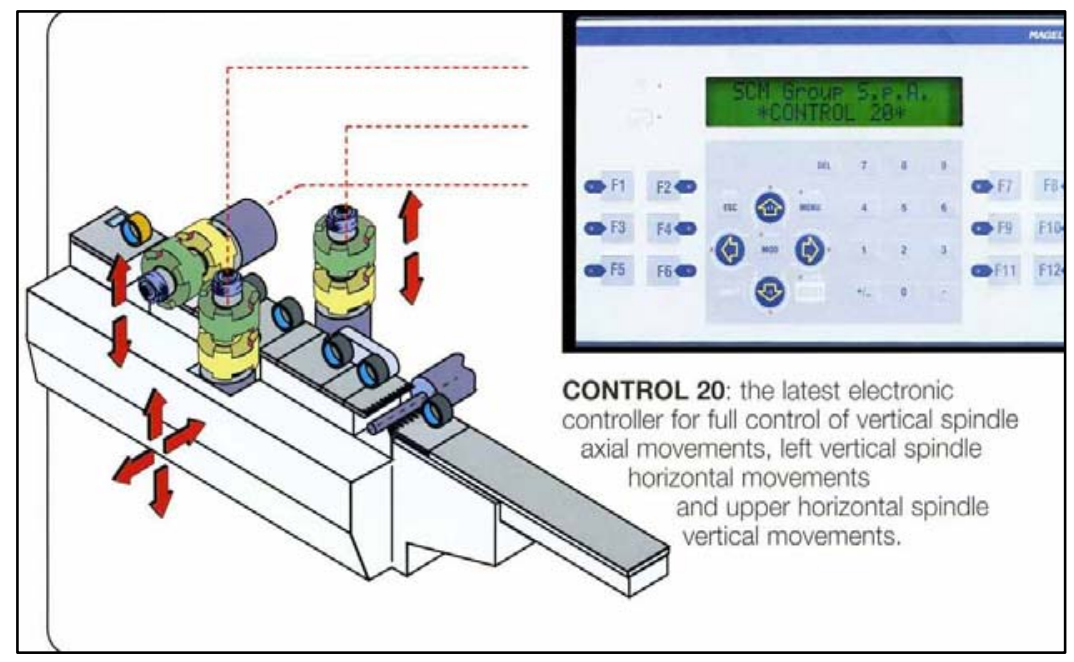

Figure 22: CNC spindle adjustment. Source: SCM brochure "Superset Class".

It is important to note that the same machine can have a combination of different spindle positioning systems, for example, the spindles that need to be adjusted more often might have $\mathrm{CNC}$ positioning, while the spindles that are rarely changed have mechanical readouts. Also, a spindle can have one type of positioning system for radial adjustment and another for axial adjustment. 


\subsubsection{Options}

Options or extras are features that can be added to the machine to improve the operation or for special operations, customized production and individual requirements. Some common examples are grooved beds, tiltable spindles and universal spindles.

\subsection{Grooved bed}

A set of grooving cutters on the first bottom spindle cut guiding grooves into the workpieces over the full width. Only the right-hand groove is machined for a close fit as a location groove. The workpiece is held firmly into the corresponding grooves in the bed plates as the stock passes between the side heads, top heads and the last bottom head, where the grooves are machined out (Clark et al, 1987). Figure 23 shows how a grooved bed works.

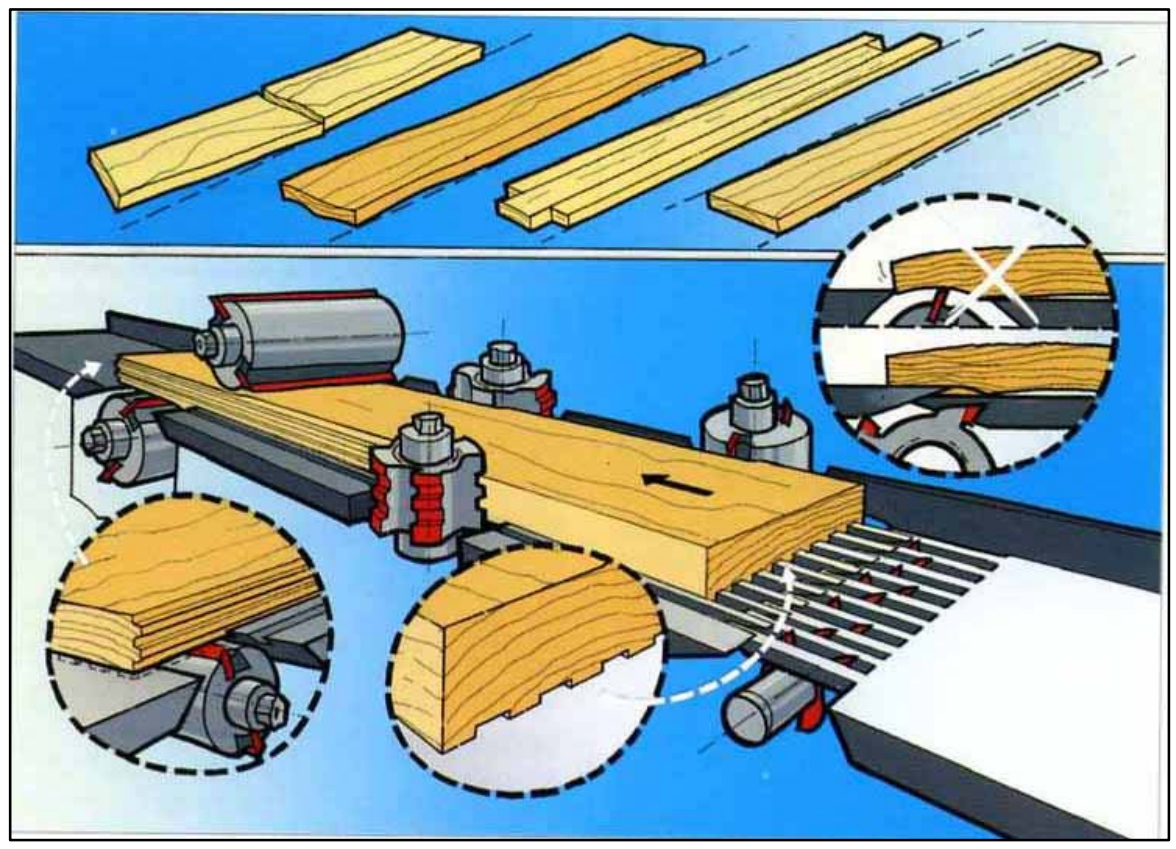

Figure 23: Grooved bed for short, twisted and untrimmed pieces. Source: Weinig brochure "The powerful extras for Weinig moulders". 
The grooved bed is recommended for short, twisted and untrimmed stock. When the wood is twisted or bowed it can dip down into the bottom head(s) and "rock" as it passes across the head. The grooved bed prevents such rocking. Out of square ends cause shorter stock to push against each other at angles, resulting in a tendency to skew. The grooved bed maintains the pieces in line (Clark et al, 1987).

\subsection{Tiltable Spindles}

Tiltable vertical spindles can be rotated up to 45 degrees from the vertical. This capability enables the operator to make beveled edge cuts with a straight knife head (Clark et al, 1987). Tilting sideheads permit angled saw cuts and varied bevels on the edges of the workpiece without changing knives (Koch, 1986).

\subsection{Universal Spindles}

Universal spindles are spindles that can be tilted to any degree required while making cuts on the top, bottom or sides of the stock (Clark et al, 1987). Universal spindles are normally last in the arrangement. Figure 24 shows a universal spindle for a 6 spindle moulder.

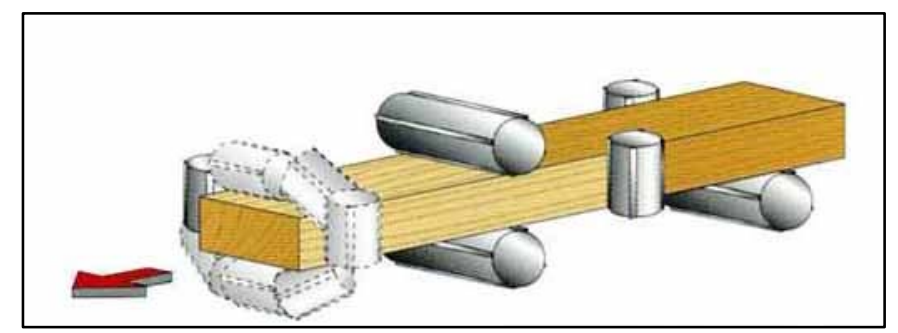

Figure 24: Universal spindle. Source: SCM brochure "Superset"

Other options include:

- Straightening table 
- Jumping spindles for non-continuous profiling

- Special right hand fence for veneered pieces

- Linear meter/feet counter

- Working hour counter

- Lateral pressure roller opposite first right-hand spindle for short pieces

- Lateral pneumatic pressure rollers for heavy timber and high speeds

- Hydraulic or electric mobile spindle for random widths

- Automatic jointers

- Pneumatic pressure bar before top spindle for varying thickness

- Pneumatically controlled feed rollers for varying thickness

- Guiding knife inserts for short pieces

- Lateral feed for short pieces

- Reduced distance between feed rollers for short pieces

- Table plate for wood inserts for mounting circular saws

- Backlash protection when sawing

- and many more.

As competition increases and patents expire, some options become part of the standard machine.

\subsection{Peripheral milling parallel to grain}

Moulding, like planing is a peripheral milling process. Peripheral milling or planning can be defined as: 
"The removal of excess wood in the form of single chips formed by intermittent engagement with the workpiece of knives carried on the periphery of a rotating cutterhead." (Koch, 1985)

The cutterhead usually carries several knives, removable for sharpening or changing, which are precisely adjusted to cut on a common cutting circle. The machined surface therefore consists of individual knife traces known as knife marks (Koch, 1985). Figure 25 illustrates the nomenclature of the process, where:

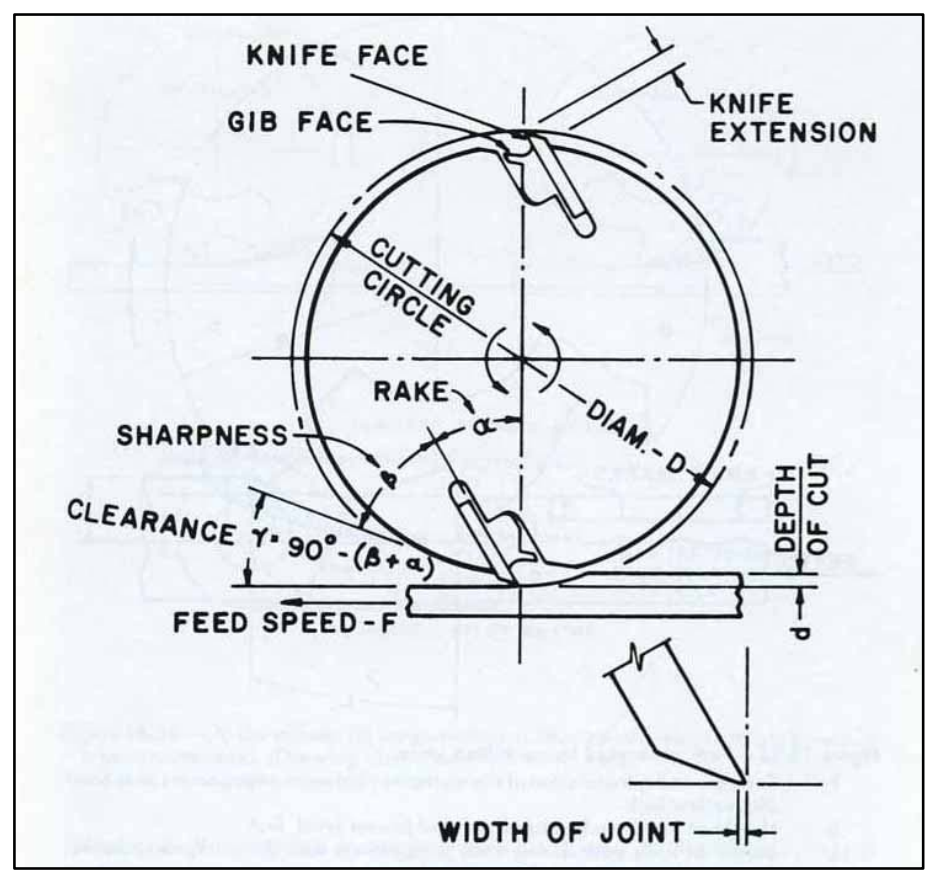

Figure 25: Terminology for peripheral milling. Source: Koch, 1985.

$$
\begin{aligned}
& \alpha=\text { Rake angle, degrees } \\
& \beta=\text { Sharpness angle, degrees } \\
& \lambda=\text { Clearance angle, degrees } \\
& d=\text { Depth of cut, inches }
\end{aligned}
$$


$D=$ Cutting-circle diameter, inches

$F=\quad$ Feed speed of workpiece, feet per minute

In planers and moulders the knives move counter to the movement of the workpiece. This is called up-milling or conventional cutting. When the knives move in the same direction as the workpiece, the process is called down-milling (Koch, 1985) or climb cutting (Effner, 1992). See Figure 26 a) and b). The trochoidal path taken by each knife tip can be represented by considering the workpiece fixed in space and allowing the cutterhead to rotate about a roll circle of a diameter that gives a relative translatory velocity equal to the desired feed speed as illustrated in Figure $26 \mathrm{c}$.

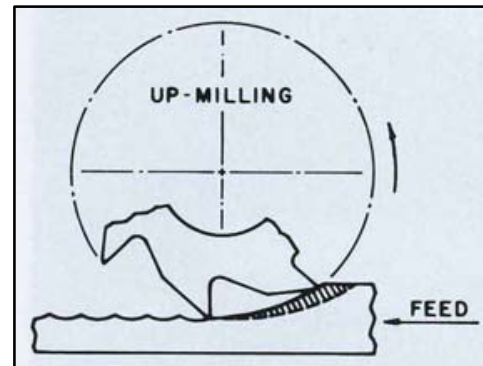

A

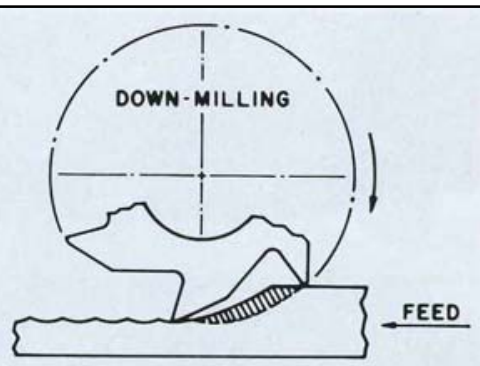

B

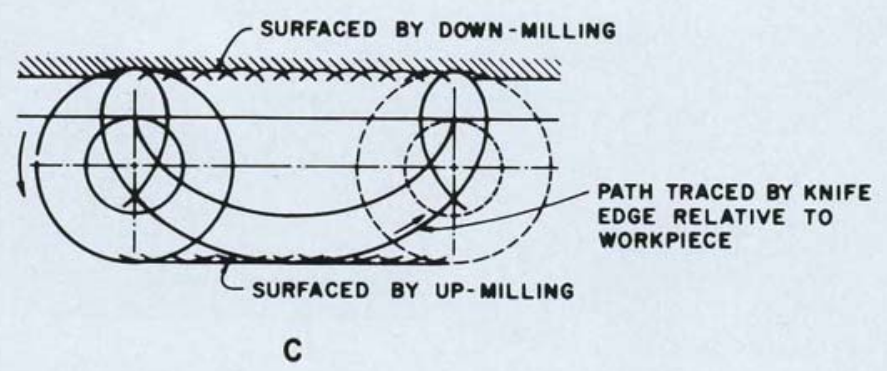

Figure 26: a) up-milling, b) down-milling, c) knife path, relative to workpiece. Source: Koch, 1985. 
This way the feed per jointed knife $\left(\mathrm{F}_{\mathrm{t}}\right)$ or distance between knife marks can be stated:

$F_{t}=12 \mathrm{~F} / \mathrm{T} \cdot n(\mathrm{Koch}, 1985)$

Where:

$T=$ number of jointed knives

$n=$ revolutions per minute $(\mathrm{rpm})$

The distance between knife marks can be reduced by decreasing the feed speed, increasing the number of jointed knives in the cutterhead, or increasing the cutterhead speed (Koch, 1985).

If the knives are accurately jointed, for up-milling the wave height can be expressed

as:

$h=F_{t}^{2} / 8\left(R+F_{t} T / \pi\right)($ Koch, 1985)

Wave height can be reduced by increasing the radius of the cutterhead or by decreasing the feed per knife (Koch, 1985).

\subsubsection{Chip Formation}

The initial up-milling cut is essentially parallel to the grain, but the emerging is at an angle to the grain. Furthermore, in peripheral up-milling the chip thickness constantly changes from a minimum value at contact to a maximum just prior to emergence. The part of the knife path that remains visible on the machined surface is the initial portion where chip thickness is minimal (Koch, 1985). 


\subsubsection{Surface Quality}

The quality of the machined surface results primarily from the cutting geometry and type of chip formed. Generally, better surface quality means shorter distance between knife marks or higher number of marks per inch and low height of knife marks as shown in Figure 27. The knife marks per inch (KMI) are calculated as:

$K M I=1 / F_{t}$

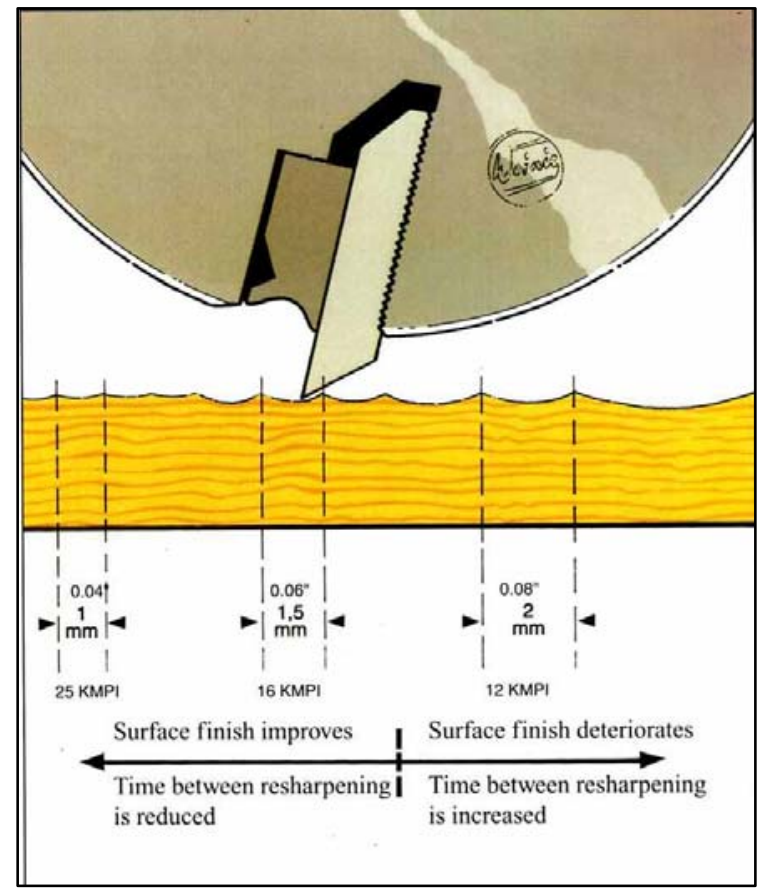

Figure 27: Surface quality relative to number of knife marks per inch (KMI). Source: The Leitz Lexikon, $4^{\text {th }}$ edition.

\subsubsection{Defects}

The most common defects encountered when planing wood are:

- Chipped grain, caused when splits run below the cutting plane, is the most damaging planing defect to surface quality in hardwoods (Koch, 1985). 
- Fuzzy grain is a particular problem when cutting wet wood with knives of low rake angle (Koch, 1985).

- Raised grain, a roughened condition in which hard portions of the annual ring are raised above the softer portion after the wood is exposed to humidity, is caused by dull or over jointed or knives with not enough clearance angle (Koch, 1985).

- Chip marks are caused by shavings or fiber bundles that fold over and adhere to the cutting edge so that they are carried around and indented into the surface of the wood (Koch, 1985).

- Burned marks in the surface when the tool rotates in the static workpiece or when the cutting speed is too high or too slow (Leitz, 2005).

- Irregular planing marks caused by an imbalanced tool, vibrations through motor, insufficient work piece clamping and/or damaged motor bearing (Leitz, 2005).

\subsubsection{Defect Control}

- Knives should be reground when the jointing plane becomes about $0.79 \mathrm{~mm}(1 / 32 \mathrm{in})$ wide to avoid washboard effect. For effective jointing, spindle bearings must be precise, cutterheads must be balanced (Koch, 1985) and runout must be prevented.

- The higher the number of knife cuts per inch (or length of knife marks in mm) the lower the number of planing defects, the relationship shows a logarithmic curve (Koch, 1985).

- Optimum moisture content for machining hardwoods is between 8 and 12 percent (Koch, 1985). 
- Rake angle is a major determinant of surface quality, but sensitivity to rake angle varies with species (Koch, 1985).

- Subsequent processing such as sanding is sometimes needed to remove chipped grain (Koch, 1985).

- The most severe chipped grain occurs at approximately $10 \%$ slope of grain, which is frequent near knots and areas of cross grain. The most severe defects occur at pockets of short grain, and the depth of such defects appears to be independent of the rake angles and feed rates. Chip-outs occur most frequently on the heart side of boards and often near an overgrown knot or associated to wavy grain. To reduce defect occurrence, such areas are often removed before moulding (Koch, 1985).

- Actions to prevent burn marks include: continuous feed, reducing jointing processes, regrinding knives, reducing RPM and adjusting the number of cutting teeth (Leitz, 2005).

- Irregular planing marks can be avoided by checking and balancing tools and motors, correcting feed and carriage units, and reducing bearing and spindle tolerances (Leitz, 2005).

\subsection{Economic Considerations}

As seen in the section "About Moulders", the woodworker has a wide variety of options to choose from when purchasing a moulder. According to its configuration, specifications, brand and country of origin, the price of a moulder can also vary greatly from anything as low as $\$ 15,000$ to approximately half a million dollars. However, not only the 
price is important. The productivity of the machining process also needs to be taken into account.

Koch (1985) describes the productivity of a moulder by the following formula:

$P=V(60 T-C X)(Y)(K)$

Where:

$P=$ lineal footage of mouldings produced per shift

$V=$ feed speed, feet per minute

$T=$ length of shift, hours

$C=$ idle machine time due to each pattern change, minutes

$X=$ number of pattern changes per shift

$Y=$ pattern multiples

$K=$ continuity of feed, percent efficiency expressed as a decimal fraction. This factor must include all non-machining time due to all causes other than pattern change.

According to Ratnasingam et al., (1996) productivity in wood machining processes has two essential dimensions: the resultant surface quality and the cost incurred in producing the surface. Machining-related cost can account for $23 \%$ of the total production cost, and improvements in machining processes will lead to better production throughput and reduced unit cost (Ratnasingam and Perkins, 1999).

One of the failings of the current product costing system in the furniture industry is the treatment of machining cost as an indirect cost, as a percentage of direct labor costs. This 
practice does not provide the necessary information to measure the productivity of the process (Ratnasingam and Perkins, 1999).

For Ratnasingam and Perkins (1999) the machining cost in the furniture industry is the total sum of four other cost elements, as described in the equation:

$C_{T}=C_{c}+C_{h}+C_{t}+C_{n}$

where $\mathrm{C}_{\mathrm{T}}$ is the total machining cost, $\mathrm{C}_{\mathrm{c}}$ is the machining cost, $\mathrm{C}_{\mathrm{h}}$ is the tools change cost, $\mathrm{C}_{\mathrm{t}}$ is the tooling cost, and $\mathrm{C}_{\mathrm{n}}$ is the nonproductive cost. The four cost elements are calculated as follows:

$C_{c}=R_{c} \cdot L \cdot \pi \cdot D / 12 \cdot F \cdot V$

$C_{h}=R_{c} \cdot L \cdot \pi \cdot D \cdot t_{1} / 12 \cdot F \cdot V \cdot T$

$C_{t}=C_{e} \cdot \pi \cdot D \cdot L / 12 \cdot F \cdot V \cdot T$

$C_{n}=R_{c} \cdot t_{n}$

where:

$R_{c}=$ overhead charge rate (USD/hour),

$L=$ length of cut (feet),

$D=$ diameter of the cutter (inches),

$F=$ feed rate (feet per minute),

$V=$ cutting speed (feet per second),

$T=$ tool life (minutes),

$t_{1}$ is the tool change time,

$t_{n}=$ nonproductive time, and 
$C_{e}=$ tool cost

The $R_{c}$ factor constitutes power consumption and machine depreciation rates, but there are no instructions on how to calculate it.

In his book "Wood Machining Processes - A managerial perspective", Ratnasingam gives a similar way of calculating the machining cost as the total sum of the tooling cost, machine hour, labor hour (including set-up time) and power consumption. The equation for the tooling cost is:

Cost per meter production for lifetime of 1 tool $=(A+(B+C)) /(C+1) \cdot D$

where:

$A=$ price of a new tool,

$B=$ cost per grinding,

$C=$ number of grindings, and

$D=$ edge life per grinding.

To obtain the tooling cost, the result is apparently multiplied by the daily production in linear feet or meters and divided by the life of tool in the same unit of length.

Ken Susnjara in his book "Furniture Manufacturing in the New Millenium" (1998) pointed out the importance of considering maintenance cost, set up cost, material handling cost and inventory cost in addition to machine and labor cost. Although the book was 
intended for current and potential users of $\mathrm{CNC}$ routers, its concepts for cost structure where considered relevant for this research and are summarized in the following lines:

Susnjara expresses the machining cost as the cost to process a part through a production center with the following formula:

Processing Cost $=$ Machine Cost + Labor \& Overhead + Tooling Cost + Handling Cost where:

Machine Cost $=$ Capital Cost + Maintenance Cost + Floor Cost

The Capital Cost, taking into account the price of the machine and its installation, the depreciation of the machine, the interests paid and the opportunity cost, is calculated as:

Capital Cost $=$ Depreciation (straight line) + Interest (paid or lost)

For the Maintenance Cost, Susnjara suggests to take the entire maintenance department cost, labor, overhead, parts, etc. and distribute the appropriate part of the entire cost to each of the machines using a "fair" formula.

Floor Cost $=$ Cost of Factory Space + Carrying Cost of Inventory

In addition, the set-up time needs to be taken into account in the Machine Cost as part of a cost per run.

Labor and Overhead Cost $=$ Set-up Labor and Overhead + Processing Labor and Overhead 
According to Susnjara, there is a cost associated with specifying, purchasing, mounting, sharpening and replacing tools. How this Tooling Cost is calculated depends on what is being evaluated. In many processes the tooling cost is a significant part of the overall processing costs and must be examined carefully. When a process or production structure needs to be evaluated, where tooling cost, life or other factors are not essentially the same, a tooling analysis needs to be included. In doing these analyses, not only the cost of the tools but also the labor and machine time required for the tooling change need to be examined if the change occurs during a production run. If the tool changes occur only during set-up, the tool change time should be included in the overall set-up time.

For Susnjara, the handling cost is the cost associated with bringing the material to the production machine from wherever they were located before. The cost of removing the finished parts is associated with the next production center. The equation for the Handling Cost is:

\section{Handling Cost $=$ Equipment Cost + Labor and Overhead}

Here the equipment costs include the depreciation and capital costs as described for the machine cost, applied to the material handling equipment, which can be a fork truck, conveyor or other machines (Susnjara, 1998).

Annamalai (2003) at North Carolina State University developed a software tool called The Router Economic Calculator (REC) Program to evaluate the economical implications of investing in a high speed / high power CNC router technology. This program permits the user to change the different costs involved in the production of a product based on the particular 
situation of the industry and generate a final cost of the product. Thus, labor, material cost, equipment, depreciation, and other costs can be easily changed by the used. The REC is a useful decision making tool to help industry at all levels to improve their process.

\subsubsection{Power Consumption}

The energy consumed during the machining process is a significant contributor towards the machining cost. The energy consumed is increased in shearing the fibers in the workpiece, overcoming the frictional force at the chip-tool interface and accelerating the chips produced away from the cutting interface (Ratnasingam and Perkins, 1999). The factors affecting power consumption during planing and moulding are discussed in this section.

\subsubsection{Factors Affecting Power Consumption}

Koch (1986) discussed the factors affecting power consumption based on planing of Douglas-fir and divided them into three categories: workpiece factors, cutterhead factors and feed factors. Smith (1996) found that most factors were interrelated, ruling out a clear cut determination of effect.

Koch found that the power required was directly proportional to the width of cut. Wet wood required more cutterhead power than dry wood with common rake angles but less with low or negative rake angles. He discussed that flat-grain wood would require less power to mill than edge-grain, except in woods with prominent rays. High-density woods require more power to plane (Koch, 1986). 
Cutting velocity, cutterhead diameter, rake angle, sharpness of knives and extension of the knives over the gib face directly affected power demand. Larger clearance angles and skewing of the cutterhead required less energy (Koch, 1986).

Among feed factors were feed speed and depth of cut. An increase in feed speed increased the height of the individual knife marks and the distance between them, lowering surface quality and raising cutterhead power demand. Depth of cut was positively correlated with cutterhead power demand (Koch, 1986).

Rawat, Rajput and Pant (1973) investigated power consumption in planing of Indian timber species with 0.37 to 0.81 specific gravity, and seasoned at $12 \%$ moisture content. The results showed that with increase in feed speed the power requirement increased but the relationship was not linear. The increase in power was less than proportional to the increase in feed rate. This fact was more dominant at higher speeds. The relationship between depth of cut and power requirement was linear and proportional. There was a significant linear relationship between specific gravity and power requirement. There was no definite relationship between cutting angle and power requirement in the range of $15^{\circ}$ to $30^{\circ}$.

Effner (1992) developed a slide rule called the "Woodworker's Calculator", which is widely used in the industry and tells the woodworker the depth of cutter marks, the mean chip thickness, the knife marks per inch, the feed rate and the approximate horsepower. The horsepower calculation is based on a feed rate of 200 inches per minute and the calculations are said to come from laboratory findings, but there is no equation provided.

Smith (1996) investigated power consumption of a CNC router for various wood machining operations. The workpiece materials used in the study were particleboard with 
melamine paper, medium density fiberboard, red oak and loblolly pine. The machine related factors evaluated included: workpiece feed speed, spindle rpm, conventional versus climb cutting, depth of cut, and width of cut. The range for spindle rpm considered in the study was between 5000 and $18000 \mathrm{rpm}$. The feed speed was between 90 and 360 inches $/ \mathrm{min}$. The depth of cut was between 0.25 and 1.0 inches and the width of cut for the experiments was 0.375 and 0.75 inches. The workpiece factors considered were species, moisture content, and grain orientation. The cutter related factors investigated were tool diameter, rake angle, and knife sharpness. Three cutter diameters $(0.75,2.5$, and 4 inch $)$ were considered. The conventional 20 degree rake angle and a 15 degree clearance angles were used in the experiments.

Figure 28 shows the trends found for most of these parameters. It can be noted that the main factors influencing power consumption during routing are the width of cut, and the depth of cut.

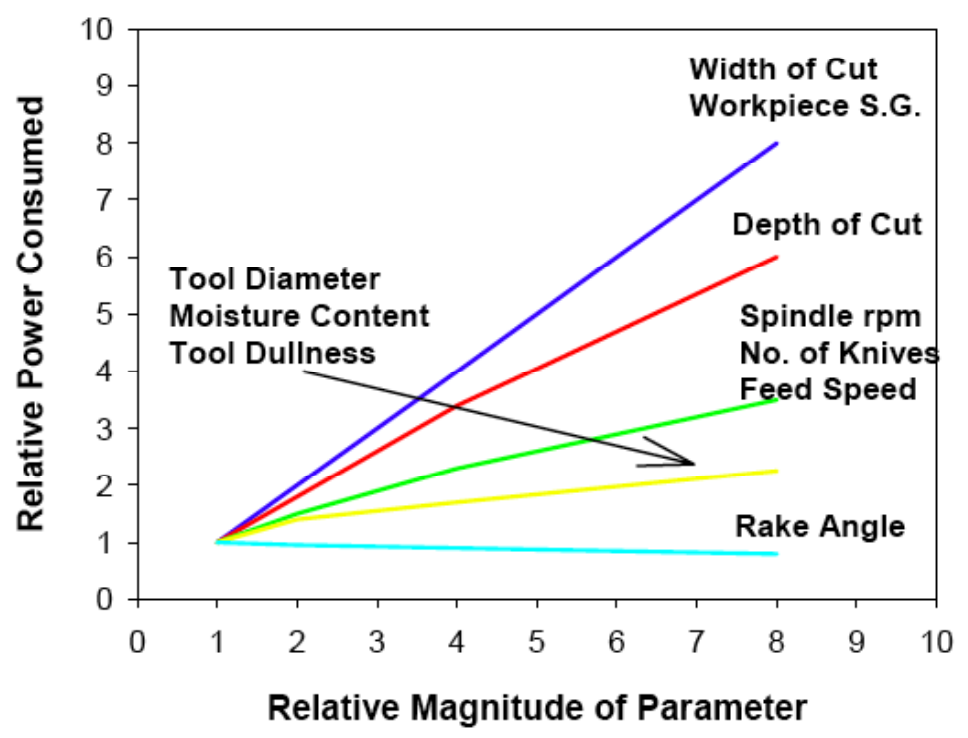

Figure 28: Typical increase in power with parameter value for selected wood 


\subsubsection{Power Consumption Estimation}

Based on similitude expressions, Smith developed the following model for estimating power consumption:

Cutting Power $\approx$ Powerref $*$ (width of cut/width of cutref) ${ }^{a} *\left(\right.$ feed speed /feed speedref) ${ }^{b} *$ depth of cut/depth of cutref) ${ }^{c} *$ (spindle rpm/spindle rpmref) ${ }^{d} *$ (tool diameter/tool diameterref) ${ }^{e} *$ (no. of flutes/no. of flutesref) ${ }^{f} *$ (rake angle /rake angle ref) ${ }^{g} *$ (tool sharpness/tool sharpnessref) $)^{h}$ (specific

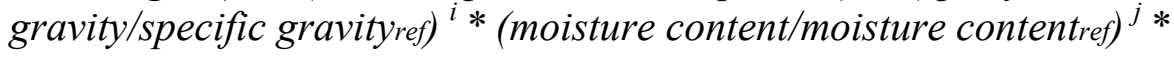
(buried cut multiplier) * (blind cut multiplier) * (grain direction multiplier)

Where the important parameters as determined by Smith are expressed in terms of ratios of the parameter of interest to a reference value of the parameter, raised to the appropriate power (exponents a, b, c ..., etc.). The reference parameter values as selected by Smith are arbitrary and correspond to a typical low speed routing operation (Annamalai, 2003). The reference parameter values used by Smith are shown in Table 1. The exponents assigned to the variables of interest were based on physical considerations, pertinent literature, and agreement with the limited experimental data. The multipliers adjust the model for other cutting conditions such as blind or buried cut, grain orientation, and machining process (Smith,1996). These exponents and multipliers appear in Table 2. 
Table 1: Reference parameter values for use in power prediction equation for conventional routing operations (Smith, T.J. 1996).

\begin{tabular}{|l|l|}
\hline Reference Parameter & Reference Value \\
\hline Reference Power & $2 \mathrm{HP}$ \\
\hline Workpiece Material & Particleboard \\
\hline Specific Gravity & 0.77 \\
\hline Tool Diameter & 2.5 inches / 0.75 inches \\
\hline Number of Cutter Knives (flutes) & 1 \\
\hline Spindle Rotational Speed & $18,000 \mathrm{rpm}$ \\
\hline Width of Cut & 0.75 inches \\
\hline Depth of Cut & 0.25 inches \\
\hline Feed Speed & 360 in/min \\
\hline Rake Angle & 20 degrees \\
\hline Tool Sharpness & $85 \mathrm{~m}$ \\
\hline Workpiece Moisture Content & $6.4 \%$ \\
\hline Milling Process & Conventional Cutting \\
\hline
\end{tabular}

Table 2: Power exponents and multipliers used in the power prediction model for conventional routing operations (Smith, T.J. 1996).

\begin{tabular}{|l|l|}
\hline Parameter & Exponent \\
\hline Width of Cut & 1 \\
\hline Depth of Cut & 0.90 \\
\hline Feed Speed & 0.50 \\
\hline Spindle Rotational Speed & 0.50 \\
\hline Tool Diameter & 0.25 \\
\hline Number of Cutting Flutes & 0.50 \\
\hline Rake Angle & -0.11 \\
\hline Tool Sharpness & 0.20 \\
\hline Workpiece Moisture Content & 0.30 \\
\hline Workpiece Specific Gravity & 1 \\
\hline & Multiplier \\
\hline If Buried Cut & 1.39 \\
\hline If Cross Grain (Hardwood/Softwood) & $1.82 / 1.50$ \\
\hline If Blind Cut & 1.25 \\
\hline
\end{tabular}

The exponents and multipliers found by Smith have been found to be reasonably accurate for conventional low speed (less than $500 \mathrm{in} / \mathrm{min}$ ) routing operations for non-buried cuts. However, these exponents are not suitable for predicting horsepower and torque 
requirements for high speed machining operations using small diameter tools in buried (parting) cut applications changes in the workpiece/tool interactions, interaction between the parameters and the fact that volumetric material removal power laws used in metal working are not applicable to wood machining due to the different chip formation regimes and the "split ahead" phenomena which occurs in wood machining (Annamalai, 2003).

Annamalai (2003) conducted experiments on high speed machining of plywood sheets with a CNC router to refine the power prediction exponents for use in high-speed buried (parting) cutting conditions in use in the manufacture of upholstered furniture components. The experimental work focused on the most important power related parameters (feed rate, spindle rpm, width of cut, depth of cut) and the most important aspects of the tool (diameter, number of flutes, helix angle, edge sharpness).

The power consumption of a reference cut was compared to the power consumption with a specific parameter varied (over a range of feed speeds and rpms). The effect of width of cut, tool sharpness, buried cut depth/tool diameter, and tool helix angle was evaluated at three spindle rpms $(10,000,15,000$, and 18,000) and five feed speeds $(250,500,1000,1500$, and 2000 inches per minute). Annamalai developed a Visual Basic computer program consisting of an input section for entering the machining and tooling conditions and an output section which indicates the average power consumption and related information on feed per tooth and gullet loading for chip removal calculations, etc.

Unpublished work by Stewart at the WMTRP focused on the development of a power consumption calculator for moulders based on the work by Smith, but the verification of the model is still pending. 


\section{METHODOLOGY}

\subsection{Moulder Economic Calculator (MEC) Program}

The basic idea of the Moulder Economic Calculator (MEC) Program is to provide a simple method for determining the improvements that may occur for a particular machining operation through the acquisition of a new moulder. It allows the user to compare between different types of moulder configurations. The MEC Program uses Labview ${ }^{\mathrm{TM}}$ software for $^{\mathrm{s}}$ input and output data and requires a basic knowledge of the machine capabilities and of the production requirements. It is based on economic considerations of the wood machining process. The following steps were followed to create the program:

- Examination of technical and economic aspects of the moulder from the literature review.

- Consultation with machine experts: experts in wood machining research as well as wood machining companies were asked about the factors that determine machining cost for moulders, the functioning of the different features, the steps of the setup process and the type of outcome expected from the program.

- Consultation with moulder users: a questionnaire was sent out to companies from the Wood Component Manufacturers Association that use moulders in their daily operations. The questionnaire asked for information on machine configuration, setup times, production parameters and production costs. A copy of the questionnaire and the responses from numerous companies are provided in the Appendix. 
- Determination of inputs and outputs: the information from the literature, the feedback provided by the machine experts and the answers from the questionnaire were considered to determine the inputs and outputs of the program.

- Development of model: The program was developed using Labview ${ }^{\mathrm{TM}}$ software to create the inputs and outputs on the front panel and using algebraic equations to relate them in the block diagram.

- Validation of model: The validation process was accomplished in three steps: First, the model was presented to wood machining experts at the Forest Products Society $60^{\text {th }}$ International Convention. Then it was discussed with one of the leading moulder manufacturers. Last, it was shown to moulder users for feedback.

\subsubsection{MEC Program Inputs}

The MEC program uses input data on machine price and purchase method, machine configuration (feed speed, spindle speed, type of tool clamping system, type of spindle positioning indicators, tool design, etc.), production parameters (number of shifts per year, length of shifts, etc.) and production costs (tools, maintenance, operators). The machine price and configuration can normally be obtained from the machine brochure or quotation. The production parameters and production costs are specific for each user. The terminology for the input screen is as follows:

\subsubsection{Machine Price}

- Machine Price: This is the purchase price of the machine in US dollars. The default values are typical and the user can input values via the input box. 
- Lease: In order for the program to calculate the machine cost, the user needs to indicate whether the machine is being leased or not. When leasing, the user has to enter the lease rate and the lease period. The default values are typical and the user can change them via the input boxes. When buying the machine instead of leasing, the user needs to indicate the type of depreciation.

- Type of Depreciation: The user can choose between the Modified Accelerated Cost Recovery System (MACRS) used by the IRS or a market value based depreciation. The program uses the 7-year class for the MACRS. When choosing the market value based depreciation, the user has to indicate the useful life and the salvage value as a percentage of the purchase price. The default values are typical and the user can change them via the input boxes.

\subsubsection{Machine Configuration}

- Changeover Time: The user can enter the known amount of time it takes to make a change-over for a new job/profile. Choosing this option will ignore any other values of setup from other input buttons. However, if the user does not know the setup time, he can rely on the program to calculate it.

- Number of Spindles: Total of spindles in the machine (4-12).

- Adjustable Spindles: This is the number of spindles that are adjusted on average every time there is a changeover. The default value is set at three and the user can change it via the input box. 
- Feed Rate: Is the speed at which the workpieces are run through the machine. The range is from 0 to 500 feet per minute. The default value is typical for a conventional moulder and can be changed via the input box.

- Spindle Speed: Speed at which the spindles rotate, given in revolutions per minute (RPM). The range goes from 0 to 12,000 . The default value is typical for a conventional moulder and can be changed via the input box.

- Spindle Positioning Indicators: There are three choices: mechanical, electronic and CNC.

- Spindle Setup Time: This is the time that it takes the operator to position one spindle, including its pressure shoe and chipbreaker. The program has predetermined spindle setup times for each type of indicator: $5 \mathrm{~min}$ for mechanical, $4 \mathrm{~min}$ for electronic and $1.5 \mathrm{~min}$ for $\mathrm{CNC}$. The user can select these default values or enter the time it takes the operator to position one spindle.

- Tool Clamping System: The user can choose between conventional, hydro and HSK.

- Tool Setup Time: This is the time it takes the operator to mount a tool on the machine. The program has predetermined tool setup times for each system: 2 min for conventional, $3 \mathrm{~min}$ for hydro and $0.25 \mathrm{~min}$ for HSK. The user can select these default values or enter the setup time for changing one tool.

- Jointers: This input asks for the presence of jointers. If the answer is "no", the program assumes only one-knife finish for the surface quality. If the answer is "yes", the program uses the total number of knives per tool to determine the surface quality. 
- Number: Refers to the amount of spindles that have jointers. This number needs to be greater than zero if the user indicated that there were jointers in the machine.

- Type: There are two choices: traditional or older type jointers that need to be assembled on the machine and cassette jointers that can be pre-assembled and then mounted on the machine.

- Jointer Setup Time: It is the time it takes to change each jointer for a new profile. Traditional jointers have a predetermined setup time of 30 min per jointer and the cassette type 3 min per jointer. The user can choose these default values or enter a known value of jointer setup.

- Feed System: When the answer is "yes", the program prompts the user to add the price of the feed system to the machine price, as well as the horsepower of the feed system to the horsepower of the machine. It is also suggested to reduce the number of operators to one. The use of feed systems depends on the feed speed of the machine and the length and weight of the product, since longer boards are easier to handle unless they are too heavy. According to a personal interview with J.R. Powell, from Weinig U.S.A., feeders are normally recommended as follows:

Table 3: Recommendation of feeders according to feed speed and board length.

\begin{tabular}{|c|c|c|}
\hline Feed Speed & Board Length & Feeder \\
\hline$>30 \mathrm{ft} / \mathrm{min}$ & $<2-3 \mathrm{ft}$ & hopper \\
\hline$>60 \mathrm{ft} / \mathrm{min}$ & $<3.5 \mathrm{ft}$ & hopper \\
\hline$>90 \mathrm{ft} / \mathrm{min}$ & most lengths & lateral feed \\
\hline
\end{tabular}


The use of outfeed systems depends on the subsequent process. They are necessary when the product is to be graded or is going to another machine, but not if the product is going to be bundled or stacked as end product.

- Horsepower: This is the total amount of horsepower of the machine, including the spindle motors and the feed motor.

- Tool Diameter: Refers to the outer diameter of the cutterhead in inches. Like the previous, it is used to determine the surface quality.

- Number of Knives per Tool: This is the number of knives mounted on the cutterhead and it is used to determine the surface quality. If the machine has no jointers, the program will automatically assume a one-knife-finish and use one in its calculations. If the machine has jointers, the program will use the number of knives entered.

\subsubsection{Production Parameters:}

- Shift Length: The default value is an 8-hour shift, as is typical in the industry.

- Number of Shifts per year: This refers to the approximate number of shifts the machine will be operated over the course of a one-year period. It is used to calculate the machine cost per shift (based on typical yearly lease rate). The default value is 260 shifts ( 1 shift/day, 5 days/week, 52 weeks/year) and the user can input other values. 
- Number of Operators: This refers to the number of operators required to run the machine on a regular basis during a single shift. This does not include setup personnel. The default value is set at two, one operator for feeding the machine and the other one for tailing the machine. This needs to be changed when using feed systems. The user can enter other values via the input box.

- Jobs: This is the amount of different orders or profiles that are usually produced per shift. Each job would require a setup of spindles and tools.

- Production: Refers to the actual production or amount of linear feet that the user is currently producing or desires to produce during one shift.

\subsubsection{Production Costs}

- Operator Cost: The operator cost is more than the wage paid per hour, it should also include the costs of overhead and liability. The default value is $\$ 35 /$ hour for each operator. A specific operator cost can be entered via the input box.

- Maintenance Cost: This refers to the cost incurred per shift to maintain the machine and includes maintenance personnel, repairs, spare parts, etc. The default values are typical and the user can input values via the input box.

- Power Price: This is the price in dollars per kilowatt-hour and depends on the agreement the user has with the power company and whether he produces his own power. The default value is typical and can be changed via the input box. 
- Tooling Expenses: Refers to the total cost of tooling for the machine incurred during one year and varies according to total production, feed speed, spindle speed, workpiece material and cutting material. The user can input values via the input box.

\subsubsection{MEC Program Outputs}

The MEC program gives three types of outputs: surface quality (knife marks, pitch height), productivity (setup time, production time, flexibility) and costs. Additionally, the program indicates when certain inputs need to be changed. For example, if the time spent doing setups is greater than the available time for one shift; the program will display an error message indicating the user to enter a lower number of jobs or to change the machine configuration to meet the desired production.

\subsubsection{Surface Quality:}

- Knife Marks per Inch: Knife marks are the series of ridges produced when machining with a rotary cutter and the frequency of knife marks determines the surface finish. The more knife marks per inch, the higher the surface quality but also the faster the tool wear. It is known that the surface quality improves above 14 knife marks per inch and deteriorates below that value (Weinig U.S.A. brochure "All about tools").

- Pitch Height: This is the depth to which the cutting knives enter the wood. The workpiece surface is better the smaller the pitch height. High surface quality demands a pitch height smaller than $0.005 \mathrm{~mm}(0.0002 ")$, average quality lies between 0.005 
$\mathrm{mm}$ and $0.01 \mathrm{~mm}(0.0002 "$ and $0.005 ")$ and lower quality above $0.01 \mathrm{~mm}(0.005 ")$ (Weinig U.S.A. brochure "All about tools").

\subsubsection{Productivity}

- Changeover Time: This is the time it takes to change the tools, reposition the spindles, rearrange the pressure elements and change the jointers to prepare the machine to run a new profile as calculated by the program or as entered by the user in the Setup Time input.

- Total Setup Time: This is the total time spent in one shift doing setups. A signal is given to the user, when the setup time is greater than the available time. In this case the available time is the length of the shift, excluding idle times.

- Possible Jobs: It is the maximum number of jobs or change-overs that can be made with the given configuration and production parameters to meet the desired production, utilizing the total shift length.

- Production Time: Indicates how long it will take to meet the actual or desired production with the given number of jobs. It is a function of the production, the feed speed and the total setup time.

\subsubsection{Costs}

- Machine Cost: This is the cost of having the machine. When the machine is leased, it is the cost of leasing at a given rate of the dollar value. When the machine is purchased it is the cost born for the depreciation of the machine. 
- Setup Cost: The setup cost is calculated from the setup time and the machine cost per shift and is the cost incurred for having the machine not running during the production time.

- Labor Cost: This is the cost of having operators running the machine for the production time. The shorter the production time, the lower the labor cost because the operators can work on other machines or processes in the plant.

- Tooling Cost: The tooling cost is simply the average tool expense per shift.

- Power Cost: This refers to the electrical power cost incurred during one shift of operating the machine. Since the power consumption calculators available were developed for $\mathrm{CNC}$ routers and not moulders and require specific data on workpiece material, dimensions and cutting parameters, it was preferred to use a generic equation for power consumption based on total horsepower, power price, load and efficiency. The program assumes a load factor of $85 \%$ and a standard motor efficiency of $83 \%$. The load factor is the fraction of the motor's horsepower actually used to drive a load (MnTAP, 2003). Motors rarely operate at their full-load point. On average, they operate at $60 \%$ of their rated load (Lobodovsky et al., 1983). Since the calculation is done for the total horsepower (sum of all motors) it is assumed that there is not a full load and an arbitrary value of $85 \%$ was chosen based on a worst case scenario. Motor efficiency is a measure of how effectively the motor turns electrical energy into mechanical energy. Motor efficiency is never $100 \%$ and is normally in the neighborhood of $85 \%$. A lower value of $83 \%$ was used following the examples of the MnTAP fact sheet. 
- Maintenance Cost: The maintenance cost is basically the average maintenance expense per shift.

- Total Cost per Shift: Is the sum of the machine, setup, tooling, power consumption and maintenance costs per shift. The pie chart shows the distribution of the different costs.

- Total Cost per Shift: Translates the total cost per shift into the total cost per year, which can be useful for financial decisions.

- Machining Cost: This is the cost of machining one linear foot with the given machine price, configuration, production parameters and costs.

\subsubsection{Solution Method}

The MEC Program is based on simple algebraic equations that relate the inputs to the outputs:

- Knife Marks per Inch $=1 / \mathrm{Ft}=12 *$ Feed rate $/$ \# Knives * RPM

- Pitch Height $=\mathrm{Ft}^{2} /\{8 *[$ Tool Diameter $+(\mathrm{Ft} * \#$ Knives $/ \pi)]\}$

- $\quad$ Total Setup Time $=$ Setup Time * \# Jobs per Shift

- Setup Time $=$ Total Tool change-over time + Total Spindle Positioning Time + Total Jointers Setup Time

or

Setup Time $=$ user's value entered

- $\quad$ Total Tool Change-Over Time $=\#$ Adjustable Spindles * Tool Changing Time

- $\quad$ Total Spindle Positioning Time $=\#$ Adjustable Spindles * Spindle Positioning Time 
- $\quad$ Total Jointers Setup Time $=$ Number $*$ Jointers Setup Time

- Possible Jobs $=($ Shift Length - Production/Feed Rate $) /$ Setup Time

- $\quad$ Production Time $=($ Production $/$ Feed Rate $)+$ Total Setup Time

- Machine Cost per Shift for leased machine (MC) = Machine Price * Lease Rate * Lease Period / (Shifts per Year * Lease Period)

- Machine Cost per Shift for machine depreciated with MACRC (MC) = Machine Price / $(8 *$ Shifts per Year)

- Machine Cost per Shift for machine depreciated at market value (MC) = (Machine Price - Machine Price * Resale Value / 100) / (Useful Life * Shifts per Year)

- $\quad$ Setup Cost (SC) = Machine Cost * Total Setup Time / Shift Length

- $\quad$ Labor Cost $(\mathbf{L C})=$ Number of Operators * Operator Cost * (Production Time / Shift Length)

- $\quad$ Tooling Cost $(\mathbf{T C})=$ Tooling Expenses $/$ Shifts per Year

- $\quad$ Power Consumption $(\mathbf{P W})=$ Horsepower * $0.7457 *$ Shift Length * Power Price * Load Factor / Motor Efficiency

- $\quad$ Maintenance Cost $(\mathbf{M T})=$ Maintenance Expenses / Shifts per Year

- $\quad$ Total Cost per Shift $=(\mathrm{MC}+\mathrm{SC}+\mathrm{LC}+\mathrm{TC}+\mathrm{PW}+\mathrm{MT})$

- $\quad$ Total Cost per Year $=$ Total Cost per Shift * Shifts per Year

- $\quad$ Machining Cost $=(\mathrm{MC}+\mathrm{SC}+\mathrm{LC}+\mathrm{TC}+\mathrm{PW}+\mathrm{MT}) /$ Production 


\subsubsection{Running the MEC Program}

All the necessary applications to run the software are contained in a CD ROM. The software requires a Windows ${ }^{\mathrm{TM}}$ based operating system.

\subsubsection{System Requirements:}

- Computer: Windows 2000/XP platform Pentium III or greater or Celron $600 \mathrm{MHz}$ or equivalent processor.

- Media and System Requirements: $256 \mathrm{MB}$ of RAM and a screen resolution of $1,024 \times 768$ pixels.

\subsubsection{Step-by-Step Installation Guidelines:}

Step 1. The CD contains four files. All of these files are required to run this software. Open the file named ivrt.msi. This will install the LabView ${ }^{\mathrm{TM}}$ RunTime Engine.

Step 2. Next install the software. Open the file named MEC.exe. This will complete the installation for this software.

Note: Before using the program, the user must set the Labview program to the RUN mode.

This is done by clicking the run icon on the icon bar at the upper left portion of the Labview ${ }^{T M}$ screen. 


\section{RESULTS AND DISCUSSION}

\subsection{MEC Program Window}

Figure 29 is a picture of the final window of the MEC Program with the default values as explained in the previous chapter. The left side has the inputs and the right side the outputs. For a description of the inputs and outputs and how to run the program please review the Methodology.

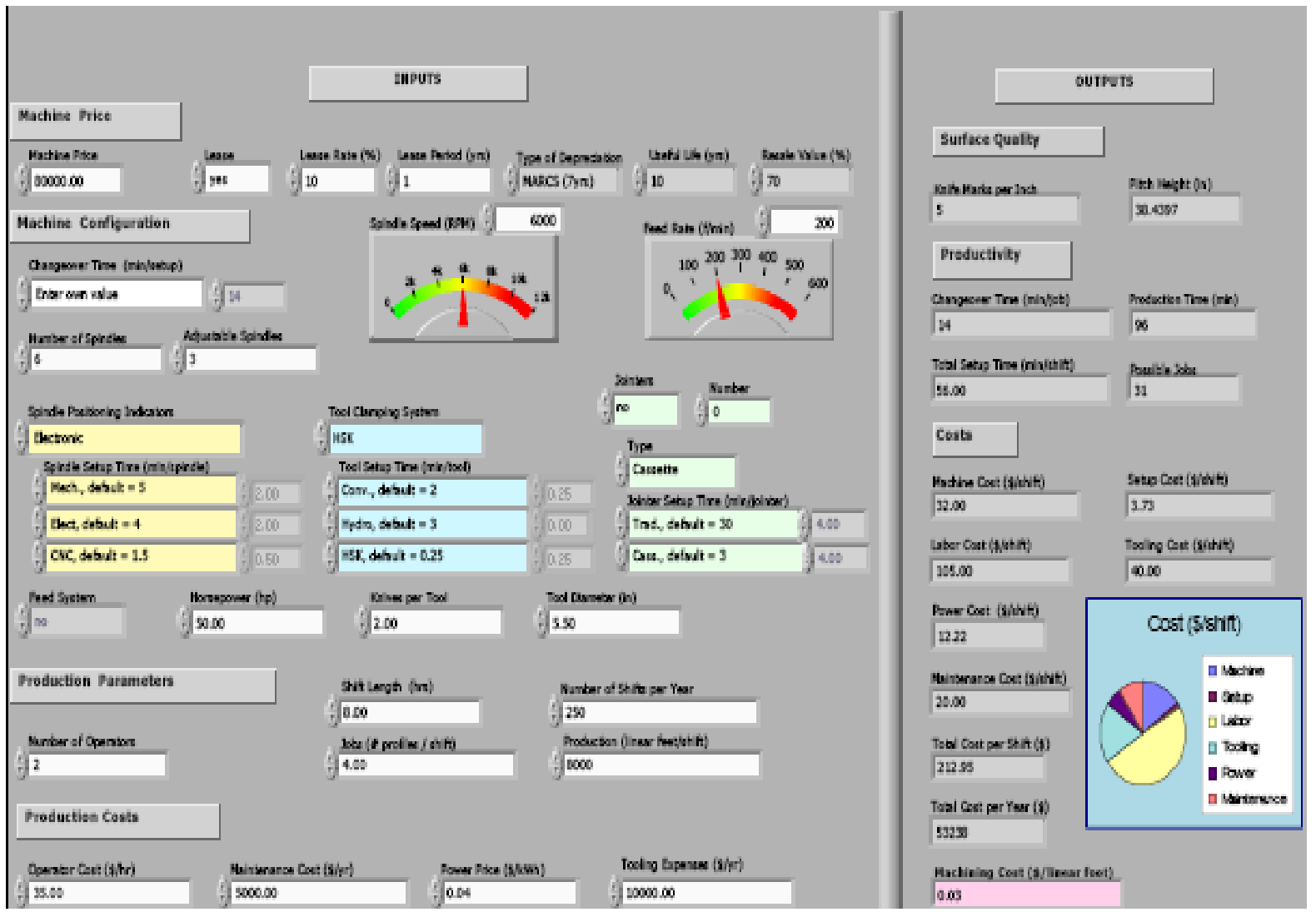

Figure 29: MEC program window with default values. 


\subsection{MEC Program Examples}

The MEC program allows the user to compare machines with different setup systems, different feed rates and spindle speeds and prices for the same production. These are some examples of the capabilities of the MEC program:

\subsubsection{Effect of Machine Price}

The sensitivity of machining cost to machine price was evaluated for a given set of conditions of machine configuration, production parameters and production costs as given in Table 4. The results in Figure 30 show that the machining cost remains constant within the evaluated price range for a given configuration. Nevertheless, for lower production runs, the machining cost is higher than for higher production runs. There is a $\$ 0.02$ difference in machining cost which means a 40\% difference between the 4,000 linear feet production and the 12,000 linear feet production.

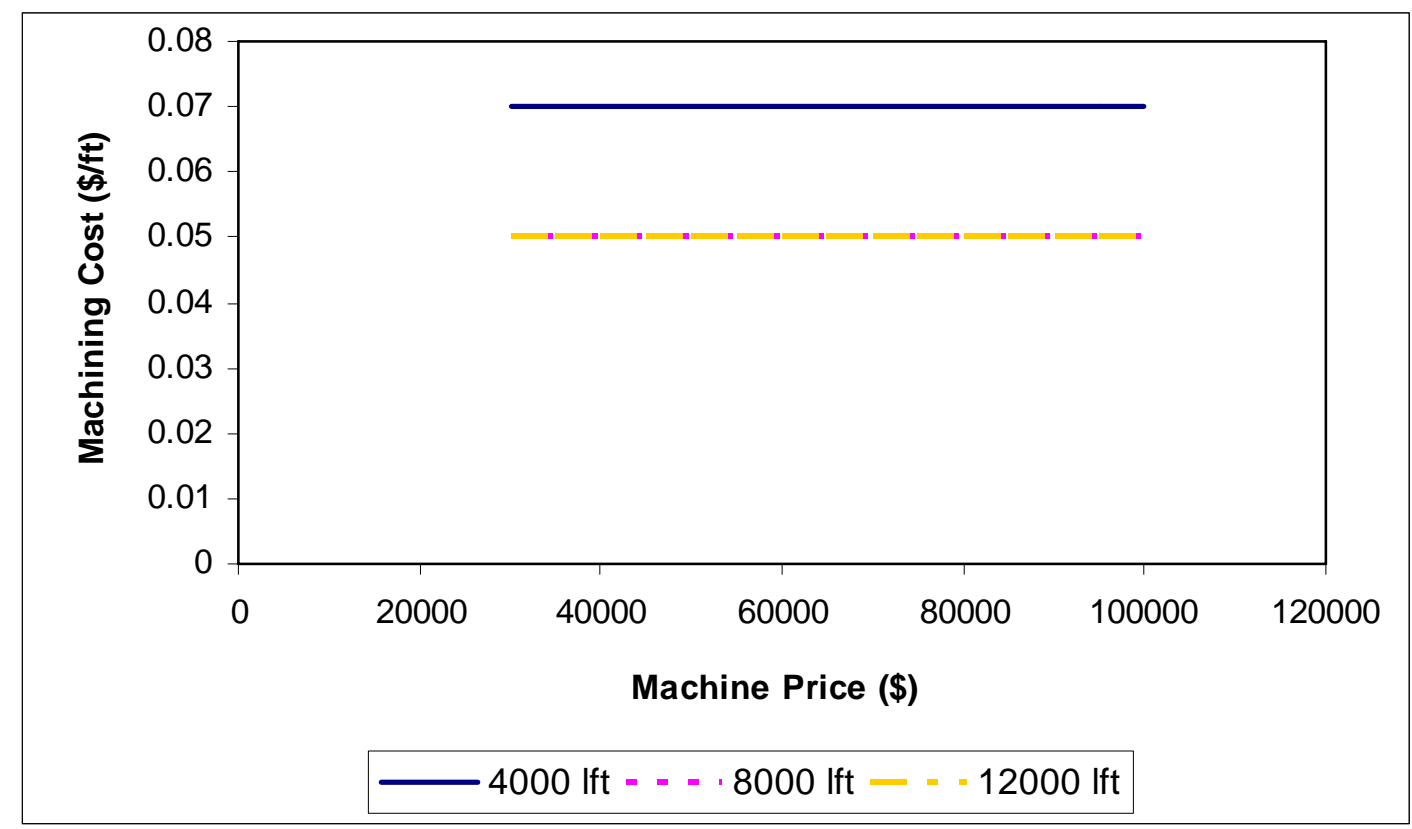

Figure 30: Effect of machine price on machining cost for different levels of production. 
Table 4: Conditions for analysis of machining cost.

\begin{tabular}{|l|r|}
\hline & \\
\hline Machine Price & \\
\hline Machine Price & yes \\
\hline Lease & $10 \%$ \\
\hline Lease Rate & $1 \mathrm{yr}$ \\
\hline Lease Period & no \\
\hline Feed System & $14 \mathrm{~min}$ \\
\hline Machine Configuration & 5 \\
\hline Changeover Time, user's value entered & 2 \\
\hline Number of Spindles & $50 \mathrm{hp}$ \\
\hline Adjustable Spindles & $5.5 \mathrm{in}$ \\
\hline Horsepower & 2 \\
\hline Tool Diameter & $\mathrm{no}$ \\
\hline Knives per Tool & $40 \mathrm{fpm}$ \\
\hline Jointers & $6000 \mathrm{rpm}$ \\
\hline Feed Rate & $8 \mathrm{hrs}$ \\
\hline Spindle Speed & 250 \\
\hline Production Parameters & 2 \\
\hline Shift Length & 4 \\
\hline Number of Shifts per Year & $2000 \$ / \mathrm{yr}$ \\
\hline Number of Operators & $0.04 \$ \mathrm{kWh}$ \\
\hline Jobs & $5000 \$ \mathrm{yr}$ \\
\hline Production & \\
\hline Production Costs & \\
\hline Operator Wage & $4,000,8,000$, and $12,000 \mathrm{lft}$ \\
\hline Maintenance Cost & \\
\hline Power Price & Tooling Expenses \\
\hline
\end{tabular}

\subsubsection{Effect of Setup Time}

Using the same inputs from Table 4, the effect of different setup times on the number of possible jobs for different feed rates was examined for a production of $8000 \mathrm{lft}$. The results given in Figure 31 show a negative power trend, with the number of possible jobs 
approaching zero as the changeover time increases. Great improvements of setup time in the number of possible jobs are clearer in the range of zero to twenty minutes per setup.

Logically, faster feed speeds also allow for higher number of setups: more than 200 jobs per shift are possible with a feed speed of $200 \mathrm{ft} / \mathrm{min}$ compared to less than 50 at $20 \mathrm{ft} / \mathrm{min}$.

Nevertheless, as the changeover time increases above $30 \mathrm{~min}$, there is not much difference between faster and slower feed speeds. Besides, one must remember, that faster feed speeds produce a lower surface quality at the same spindle speed. The effect of the changeover time on the number of jobs possible is important because companies aiming for just-in-time production need shorter setups in order to produce only the orders as they come in the system. Custom manufacturing also puts pressure on reducing the setup time, shorter setups allow for higher flexibility.

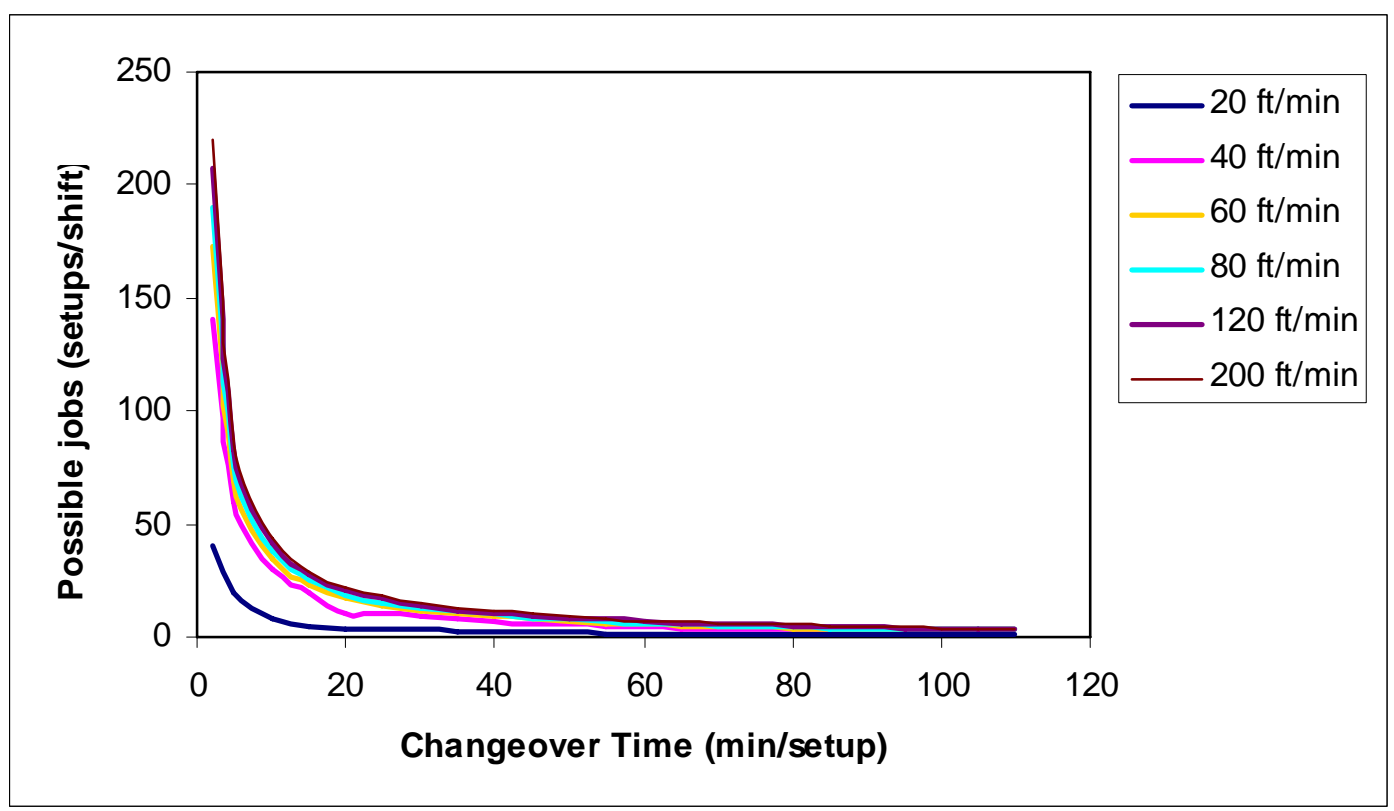

Figure 31: Effect of changeover time on the possible jobs or setups per shift. 
Figure 32 shows how the changeover time affects the total production time for different feed speeds. The intercept of the x-axes is set at $480 \mathrm{~min}$ to show where the total setup time reaches the shift length. It can be seen that as the changeover time increases, the production time increases linearly and that faster feed speeds allow the user to produce the same amount of linear feet in less time, though, as stated before, at the expense of the surface quality if the spindle speed is kept constant.

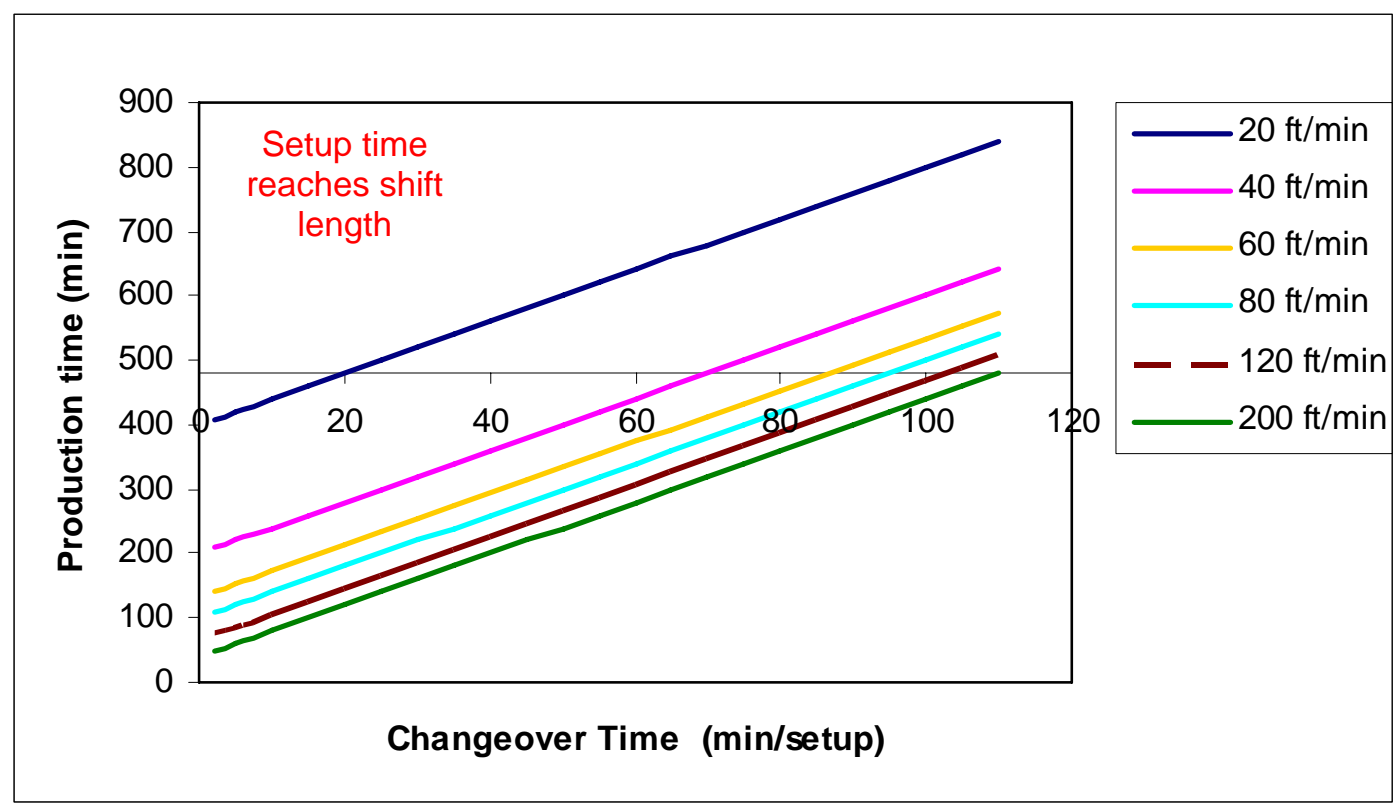

Figure 32: Effect of changeover time on production time.

\subsubsection{Effect of Machine Configuration}

Another example of the MEC Program capabilities is the comparison of different machine configurations. The effect of six different machine configurations drawn from Table 5 on machining cost was compared. When comparing machines of different configurations, it is important to take into account that faster feed speeds mean faster wear of the tools, hence 
a higher tooling cost, and that machines with technologically advanced features such as CNC and HSK have a higher purchase price. In addition, machines with HSK are capable of producing the same amount of linear feet at the same surface quality in shorter time because they can run at faster rpm. Such aspects were taken into account in this example.

Table 5: Six different machine configurations for small production and few jobs.

\begin{tabular}{|c|c|c|c|c|c|c|}
\hline Machine Price & $\$ 80,000$ & $\$ 100,000$ & $\$ 170,000$ & $\$ 150,000$ & $\$ 170,000$ & $\$ 190,000$ \\
\hline Feed System & no & no & no & no & no & no \\
\hline Setup Time & calculate & calculate & calculate & calculate & calculate & calculate \\
\hline $\begin{array}{l}\text { Number of } \\
\text { Spindles }\end{array}$ & 6 & 6 & 6 & 6 & 6 & 6 \\
\hline $\begin{array}{l}\text { Adjustable } \\
\text { Spindles }\end{array}$ & 3 & 3 & 3 & 3 & 3 & 3 \\
\hline Horsepower & 50 & 50 & 50 & 50 & 50 & 50 \\
\hline $\begin{array}{l}\text { Spindle Positioning } \\
\text { Indicators }\end{array}$ & Mechanical & Electronic & Electronic & Mechanical & Electronic & $\mathrm{CNC}$ \\
\hline Spindle Setup Time & default & default & default & default & default & default \\
\hline $\begin{array}{l}\text { Tool Clamping } \\
\text { System }\end{array}$ & Conventional & Conventional & Hydro & Hydro & HSK & HSK \\
\hline Tool Setup Time & default & default & default & default & default & default \\
\hline Tool Diameter & $5.5 \mathrm{in}$ & $5.5 \mathrm{in}$ & 5.5 in & 5.5 in & 5.5 in & 5.5 in \\
\hline Knives per Tool & 2 & 2 & 2 & 2 & 2 & 2 \\
\hline Jointers & no & no & no & no & no & no \\
\hline Feed Rate & $40 \mathrm{fpm}$ & $40 \mathrm{fpm}$ & $40 \mathrm{fpm}$ & $40 \mathrm{fpm}$ & $80 \mathrm{fpm}$ & $80 \mathrm{fpm}$ \\
\hline Spindle Speed & $6000 \mathrm{rpm}$ & $6000 \mathrm{rpm}$ & $6000 \mathrm{rpm}$ & $6000 \mathrm{rpm}$ & $12000 \mathrm{rpm}$ & $12000 \mathrm{rpm}$ \\
\hline Shift Length & $8 \mathrm{hrs}$ & $8 \mathrm{hrs}$ & $8 \mathrm{hrs}$ & $8 \mathrm{hrs}$ & $8 \mathrm{hrs}$ & $8 \mathrm{hrs}$ \\
\hline $\begin{array}{l}\text { Number of Shifts } \\
\text { per year }\end{array}$ & 250 & 250 & 250 & 250 & 250 & 250 \\
\hline $\begin{array}{l}\text { Number of } \\
\text { Operators }\end{array}$ & 2 & 2 & 2 & 2 & 2 & 2 \\
\hline Jobs & 8 & 8 & 8 & 8 & 8 & 8 \\
\hline Production & 8000 lf & 8000 lf & 8000 lf & 8000 lf & 8000 lf & 8000 lf \\
\hline Operator Wage & $35 \$ / \mathrm{hr}$ & $35 \$ / \mathrm{hr}$ & $35 \$ / \mathrm{hr}$ & $35 \$ / \mathrm{hr}$ & $35 \$ / \mathrm{hr}$ & $35 \$ / \mathrm{hr}$ \\
\hline Maintenance Cost & $5000 \$ / y r$ & $5000 \$ / y r$ & $6000 \$ / y r$ & $6000 \$ / y r$ & $5000 \$ / y r$ & $5000 \$ / y r$ \\
\hline Power Price & $0.04 \$ / \mathrm{kWh}$ & $0.04 \$ / \mathrm{kWh}$ & $0.04 \$ / \mathrm{kWh}$ & $0.04 \$ / \mathrm{kWh}$ & $0.04 \$ / \mathrm{kWh}$ & $0.04 \$ / \mathrm{kWh}$ \\
\hline Tooling Expenses & $4000 \$ / y r$ & $4000 \$ / y r$ & $10000 \$ / y r$ & $10000 \$ / y r$ & $10000 \$ / y r$ & $10000 \$ / y r$ \\
\hline
\end{tabular}


Figure 33 shows the total cost per shift for the given production. The results show that even though moulders with HSK are more expensive, the total cost of operating the machine per shift is lower than for other configurations. This is due to the fact that they can reach the same production in less time because they can run at faster speeds and produce the same quality and because less time is spent in setup so that more time can be dedicated to run the machine. The reduction in production time results in lower labor cost because the operators can be moved to other machines or processes. The importance of this result is that it can translate into thousands of dollars saved per year.

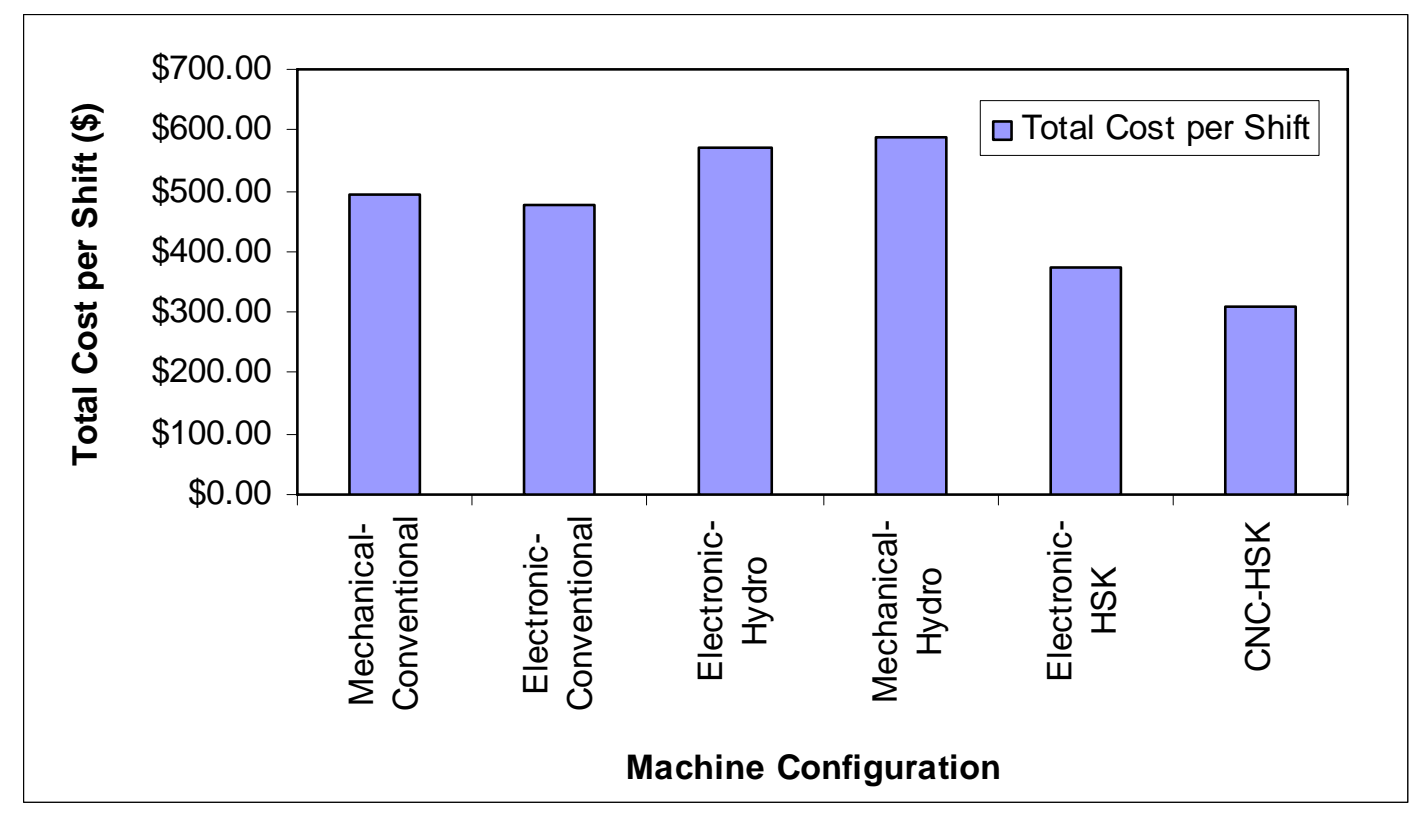

Figure 33: Effect of machine configuration on total cost per shift.

Figure 34 presents the effect of machine configuration on machining cost. The results are basically the same as for the previous example, only in dollars per linear foot: machines with HSK have a lower machining cost per linear foot than the other configurations. Although it seems that there is only a few cents of dollar of difference in machining cost 
between the different configurations this difference can amount for as much as a $50 \%$ to $80 \%$ increase.

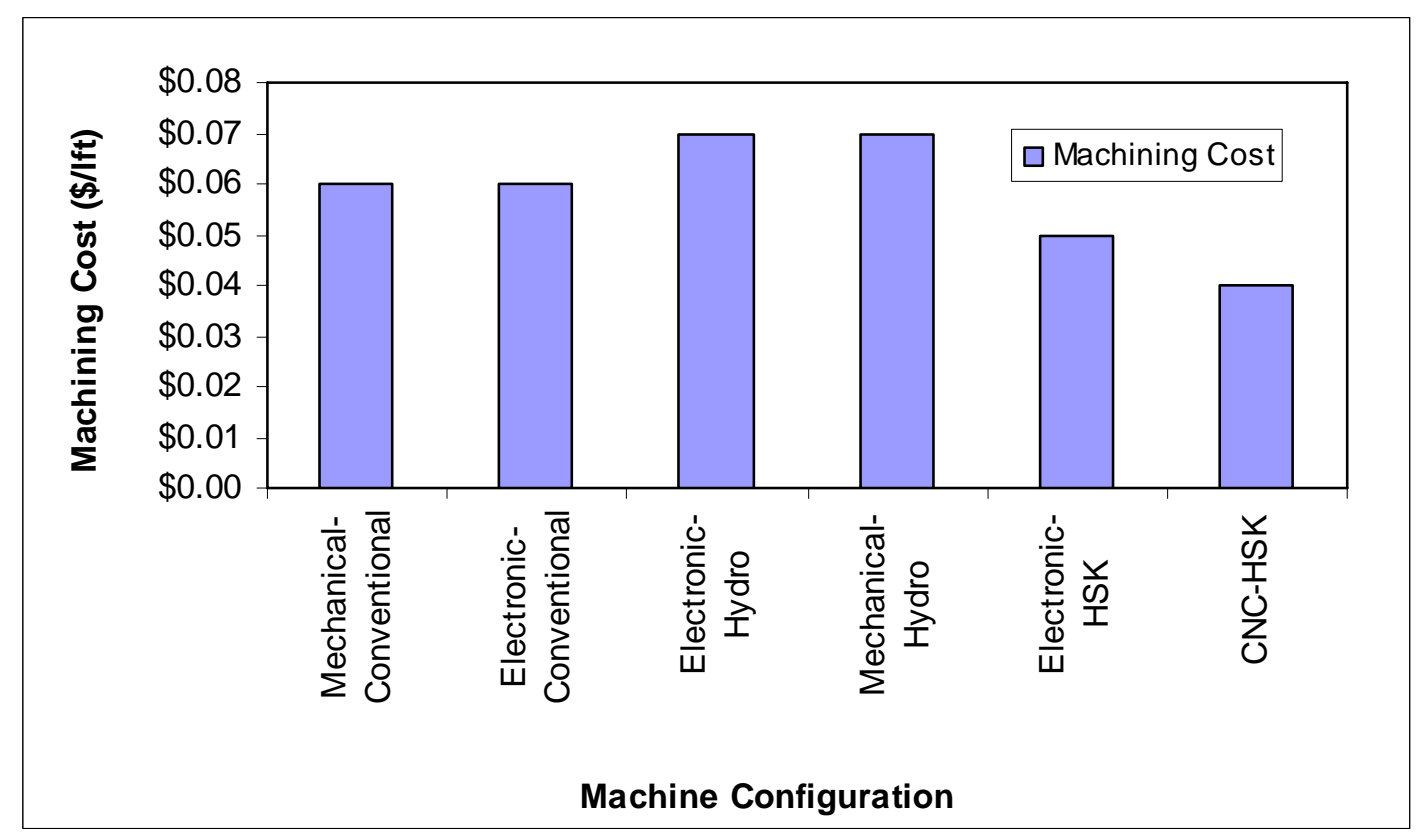

Figure 34: Effect of machine configuration on machining cost.

It must be pointed out, that the above examples are based on the given conditions and the default values, which are based on assumptions. Results may vary for different production parameters and machine configurations. Other examples of using the MEC program are possible, such as comparing the machining cost with and without feed systems, comparing between leasing and purchasing the machines, etc.

Finally, it also has to be noted, that the program does not take into account any options that may be added to the machine configuration and that may improve the operation, for example the grooved bed or the table plate for wood inserts. In making a purchasing 
decision of a moulder, the woodworker also needs to consider the risk of buying from one vendor or another with regards to after-sales service in terms of spare parts, maintenance and repairs as well as the quality of the machine itself and its resale value. 


\section{CONCLUSIONS}

- The MEC program is a flexible tool that allows the user to determine the cost of machining one linear foot of wood with a particular machine configuration, production parameters and production costs.

- The MEC program avoids mistakes by telling the user when a machine configuration is not adequate for a particular production and/or number of jobs.

- With the MEC program, the user can determine which variables most affect the machining cost.

- The MEC program also serves the user to compare between different machine configurations and determine which one is best based either on cost, production or flexibility.

- In comparing machine configurations, the user has to take into account differences in machine price, tooling cost, maintenance cost, feed speed and spindle speed.

- The MEC program shows that the machine price is not the only variable in determining the cost of machining and therefore should not be the only thing to consider in purchasing a moulder.

- Current limitations of the MEC program include: it can only analyze one machine configuration at a time and it does not account from advantages from different spindle arrangements and options that may be added, such as the grooved bed or the table plate for wood inserts. 
- The MEC program is an objective decision making tool, but the woodworker also needs to consider other aspects that cannot be quantified such as the after-sales service in terms of spare parts, maintenance and repairs as well as the machine quality. 


\section{FUTURE WORK}

Future research should focus on the following:

- Cost analysis of tools for different applications: So far this is an input of the MEC program, in other words, it is assumed that the user knows what the tool cost is, but many times this is not true and woodworkers need a way to determine their tooling cost.

- Power consumption for different applications: Although the power consumption cost appears negligible compared to the labor cost as part of the total machining cost, further research is needed to validate the power consumption calculation method used and determine differences between profile depths, materials, tools, speeds, etc.

- Determining the right configuration according to product type, production volume and quality: An ideal version of the MEC Program would prompt the user for input on product type (flooring, windows, interior millwork, etc.), material (wood species, plastics, etc.), desired production (linear feet) and quality (KMI and pitch) and suggest the right machine configuration. Feedback from industry on the current MEC Program version is still needed to achieve such an output. 


\section{REFERENCES}

Adams, L. (1992) “Pre-planning saves on moulder downtime.” Wood \& Wood Products 97(1): 78-82

Albert, M. (2000) Rapid Traverse, An alternative to HSK Modern Machine Shop. 72(1) Retrieved September 9, 2005, from http://www.mmsonline.com/articles/0100rt1.html

Annamalai, S. (2203) An Investigation of High-Speed Machining on CNC Routers used for Upholstered Furniture Manufacturing. Doctorate Thesis, North Carolina State University, Raleigh, 201 pp.

Baier, S. (2003) "Part I: Spindles and Their Relationship to High-Speed Toolholders" Moldmaking Technology. Retrieved July 21, 2006 from http://www.moldmakingtechnology.com/articles/080303.html

Clark, E.L., J.A. Ekwall, C.T. Culbreth and R. Willard. (1987). Furniture Manufacturing Equipment, North Carolina State University, Raleigh, 5-1, 14-1 - 14-17 and 31-24-25

Derning, S. (1995) Increasing Productivity “Profiling Moulder Productivity.” Wood \& Wood Products 100(2): 97-104

Destefani, J. (2002) "Holding the Precision Line" Manufacturing Engineering Magazine. 128(5): 55-64

Effner, J. (1992). Chisels on a Wheel: A Comprehensive Reference to Modern Woodworking Tools and Materials. Prakken Publications, Inc., Ann Arbor. 200 pp.

Hassel, R. Wadkin North America,"Set-Up Basics for Moulders or Preparation and Procedure" Summary of a speech presented at the Tooling and Machining for the Wood Industry Seminar, November 1-2, 2000. 
Horn, T. (2004) Static and Dynamic Runout in Woodworking Tools. Unpublished review. Koch, P. (1985). Utilization of Hardwoods Growing on Southern Pine Sites, Agriculture Handbook No. 605, Volume II: Processing, Chapter 18: Machining. U.S. Department of Agriculture, Forest Service. $2542 \mathrm{pp}$

Kocherovsky, E. (2001) “HSK: Characteristics And Capabilities”, Modern Machine Shop Online, Retrieved July 21, 2006 from http://www.mmsonline.com/articles/100105.html

Kocherovsky, E. and B. Travis. (1998) "The Secrets of HSK" Cutting Tool Engineering Magazine, 50(6): Retrieved July 21, 2006 from http://www.hskworld.com/articles/hsk_secrets/hsk_secrets.htm

Lewis, D.L. (1999) What's happening with HSK? Its popularity is growing, but it's not sweeping the nation. Manufacturing Engineering. (4): 78-80

Lobodovsky, K, .R. Ganeriwal and A. Gupta. Field Measurements and Determination of Electric Motor Efficiency. Sixth World Energy Engineering Congress, Atlanta, Georgia, December 1, 1983.

Lung, M. (2000). "Balance Matters" Manufacturing Engineering. 124(1): 66-70 MnTAP, 2003. “Motor Energy-Saving Tips” Minnesota Technical Assistance Program FACT SHEET. Retrieved July 18, 2006, from http://www.mntap.umn.edu/energy/123MotorTips.pdf

Ponsolle, Mike "Hydraulic Toolholders Minimize Runout” Fabricating and Metalworking Magazine Online. Retrieved February 18, 2004, from http://www.nds.com/article.asp?article_id=409\&channel_id=9 
Ratnasingam, J. 2002. Wood Machining Processes - A managerial perspective. Malaysia. 103 pp.

Ratnasingam, J., T.P. Ma and M.C. Perkins, (1999). "Productivity in Wood Machining Processes: A question of simple economics?" Holz als Roh- und Werkstoff 57: 51-56

Rawat, B.S., S.S. Rajput, and B.C. Pant (1973) “A Study on Power Requirement in Thickness Planing.” The Indian Forester Jan. 1973: 23-31.

Samelius, A.: ETP Transmission AB, Sweden, “Accurate Centering and Clamping Techniques" Summary of a speech presented at NC State University. July 26, 1990

Smith, T.G. (1996) An Experimental Investigation of the Power Requirements for High Speed CNC Router Spindles. Masters Thesis. Department of Wood and Paper Science, North Carolina State University, Raleigh, 109 pp.

Stewart, J.S. "The Effect of Dynamic Balance of Moulder Heads on Surface Finish" Cutting tool Business. September, 1990. p30

Susnjara, K. (1998). Furniture Manufacturing in the New Millennium, $1^{\text {st }}$ ed. Indiana, Thermwood Corporation. 241 pp.

Vance Publishing Company (1992) Moulder manufacturers aim for faster set up. Wood and Wood Products 97(5): 86-87

Weinig USA. "All About Tools" A Weinig Information Bulletin. 23 pp.

Wikipedia (2006) “Machine taper” Retrieved July 21, 2006 from $\underline{\text { http://en.wikipedia.org/wiki/Machine taper }}$

Wowk, V. (2000), Machinery Vibration: Alignment. NewYork, McGraw-Hill Wowk, V. (1995), Machinery Vibration: Balancing. NewYork, McGraw-Hill 
APPENDIX 


\section{North Carolina State University}

Wood Machining and Tooling Research Program

Campus Box 8005, Raleigh, NC 27695

Tel: 919515 1548, Fax: 9195133496

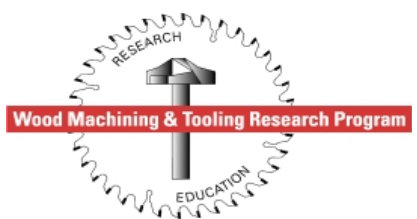

The Wood Machining and Tooling Research Program at North Carolina State University is preparing a symposium on moulders. Our objective is to provide the U.S. wood industry with useful information on the technical and economic aspects of the modern moulder. For this purpose we also need to gather information of the moulder in an industrial setting. We appreciate your cooperation in filling the following questionnaire about your moulder(s). In exchange for your cooperation you will receive a free copy of the Moulder Economic Calculator Program and the corresponding publication. Any information you provide will remain confidential and will only be used to determine general trends of the industry.

Company:

Name:

Please take a few moments to fill in the following information for each moulder in your plant:

\begin{tabular}{|l|l|}
\hline Characteristic & \\
\hline Brand / Model / Year & \\
\hline \# of spindles / Spindle Configuration & \\
\hline Total horsepower of spindle motors (hp) & \\
\hline Horsepower of feed motor (hp) & \\
\hline Spindle Speed (rpm) & \\
\hline Tool clamping system & \\
C = Conventional, $\mathrm{H}=$ Hydro, $\mathrm{K}=\mathrm{HSK}$ & \\
\hline Tool room time (min) & \\
\hline Change-over time (min) & \\
\hline Spindle positioning indicators \\
M = Mechanical, E = Electronic, C = CNC & \\
\hline Actual feed rate (feet/min) & \\
\hline $\begin{array}{l}\text { Feed System } \\
\text { M = manual, H = hopper feeder, A = Automatic }\end{array}$ & \\
\hline \# Planing Cutterheads & \\
\hline Number of operators & \\
\hline Production (linear feet/month) & \\
\hline Effective Machining Time (min/shift) & \\
\hline \# of Jobs / month & \\
\hline Machine Maintenance Expenses (\$) & \\
\hline Tool Expenses (\$) & \\
\hline Tool Maintenance Expenses (\$) & \\
\hline Workpiece materials (species) & \\
\hline Product type & \\
\hline Length of workpieces (max/min/ave. feet) & \\
\hline Material removed (max/min/ave. in $\left.{ }^{2}\right)$ & \\
\hline
\end{tabular}

Thank you for your input! 
Cell: A20

Comment: Spindle Configuration:

Look at the "Spindle Configuration" sheet, then enter the letter that corresponds to your moulder configuration.

Cell: A26

Comment: Tool room time: Refers to the time it takes to prepare the tool and grind it.

Cell: A27

Comment: Change-over time:

Refers to the time it takes change the tools and reposition the spindles every time a new job is run.

Cell: A28

Comment: Spindle positioning indicators:

Please indicate if you have a combination of systems, how many spindles have each system.

Cell: $A 30$

Comment: Actual feed rate: It is the speed at which the machine normally runs.

Cell: A36

Comment: Effective Machining Time: It is the time the machine is actually running and producing parts (no idle time).

Cell: A37

Comment: \# of Jobs / month: Consider each job represents a different profile or the need to make a new setup.

Cell: A38

Comment: Machine Maintenance Expenses: Is how much is spent in oil, spare parts, labor, etc. for the machine.

Cell: A39

Comment: Tool Expenses: Refers to purchase of knives.

Cell: $A 40$

Comment: Tool Maintenance Expenses: It is the amount spent in grinding wheels, tool spare parts, etc. for the tools.

Cell: A41

Comment: Workpiece materials: oak, cherry, maple, poplar, pine, plastic, mdf, composites, etc.

Cell: A42

Comment: Product type: flooring, millwork, mouldings, cabinet parts, furniture parts, siding, 
construction lumber, etc.

Cell: A44

Comment: Material removed:

Difference between the rough dimensions and the end profile. 


\section{Answers to questionnaire}

\begin{tabular}{|c|c|c|c|c|}
\hline Characteristic & Moulder 1 & Moulder 2 & Moulder 3 & Moulder 4 \\
\hline \# of spindles / Spindle Configuration & $\mathrm{L}$ & $\bar{Y}$ & F & $\mathrm{D}$ \\
\hline Total horsepower of spindle motors (hp) & 115 & 120 & 90 & 95 \\
\hline Horsepower of feed motor (hp) & 5 & 10 & 4 & 5.5 \\
\hline Spindle Speed (rpm) & 8000 & 7000 & 7000 & 8000 \\
\hline $\begin{array}{l}\text { Tool clamping system } \\
\mathrm{C}=\text { Conventional, } \mathrm{H}=\text { Hydro, } \mathrm{K}=\mathrm{HSK}\end{array}$ & $\mathrm{C}$ & $\mathrm{H}$ & $\mathrm{C}$ & $\mathrm{C}$ \\
\hline Tool room time (min) & NA & NA & NA & NA \\
\hline Change-over time for tools (min/tool) & 4 min average & 4 min average & 4 min average & $\mathrm{Na}$ \\
\hline $\begin{array}{l}\text { Spindle positioning indicators } \\
\mathrm{M}=\text { Mechanical, E = Electronic, C = CNC }\end{array}$ & M & M & M & M \\
\hline Setup time for spindles (min/spindle) & 4 min average & 4 min average & 4 min average & NA \\
\hline Actual feed rate (feet/min) & 28-120 FPM & 28-120 FPM & 28-120 FPM & $20-78 \mathrm{fpm}$ \\
\hline $\begin{array}{l}\text { Feed System } \\
\mathrm{M}=\text { manual, } \mathrm{H}=\text { hopper feeder, } \mathrm{A}= \\
\text { Automatic feed/outfeed }\end{array}$ & M & M & M & $\mathrm{H}$ \\
\hline \# Planing Cutterheads & 6 & 6 & 6 & 5 \\
\hline Number of operators & 1 & 1 & 1 & 2 \\
\hline Production (linear feet/month) & NA & NA & NA & 295000 \\
\hline Effective Machining Time (min/shift) & NA & NA & NA & NA \\
\hline \# of Jobs / month & \begin{tabular}{c|}
504 Jobs / \\
Month \\
Average...24 \\
Setups per \\
day avg \\
\end{tabular} & \begin{tabular}{|c|} 
505 Jobs / \\
Month \\
Average...24 \\
Setups per \\
day avg \\
\end{tabular} & \begin{tabular}{|c|}
504 Jobs / \\
Month \\
Average...24 \\
Setups per \\
day avg \\
\end{tabular} & NA \\
\hline Machine Maintenance Expenses (\$) & NA & NA & NA & NA \\
\hline Tool Expenses (\$) & NA & NA & NA & NA \\
\hline Tool Maintenance Expenses (\$) & NA & NA & NA & NA \\
\hline Workpiece materials (species) & $\begin{array}{l}\text { Maple, Oak, } \\
\text { Cherry, } \\
\text { Walnut, Fir, } \\
\text { Mahogany }\end{array}$ & \begin{tabular}{|c|} 
Maple, Oak, \\
Cherry, \\
Walnut, Fir, \\
Mahogany
\end{tabular} & $\begin{array}{l}\text { Maple, Oak, } \\
\text { Cherry, } \\
\text { Walnut, Fir, } \\
\text { Mahogany }\end{array}$ & $\begin{array}{l}\text { Oak, Soft } \\
\text { Maple }\end{array}$ \\
\hline Product type & $\begin{array}{c}\text { Architectual } \\
\text { Mouldings }\end{array}$ & $\begin{array}{c}\text { Architectual } \\
\text { Mouldings }\end{array}$ & $\begin{array}{c}\text { Architectual } \\
\text { Mouldings }\end{array}$ & $\begin{array}{c}\text { Kitchen } \\
\text { cabinet } \\
\text { components }\end{array}$ \\
\hline Length of workpieces (max/min/ave. feet) & 2'-16' 9'Avg & 2'-16' 9'Avg & 2'-16' 9'Avg & $8 / 1 / 2.5$ \\
\hline Material removed (max/min/ave. in²) & NA & NA & NA & 0.1875 \\
\hline
\end{tabular}




\begin{tabular}{|c|c|c|c|c|c|c|}
\hline Moulder 5 & Moulder 6 & Moulder 7 & Moulder 8 & Moulder 9 & \begin{tabular}{|l|} 
Moulder 10 \\
\end{tabular} & Moulder 11 \\
\hline $\mathrm{P}$ & $\mathrm{F}$ & $\mathrm{L}$ & A & $5 / \mathrm{B}$ & 6/D & 5/B \\
\hline 125 & NA & NA & NA & NA & NA & NA \\
\hline 10 & $\mathrm{NA}$ & $\mathrm{NA}$ & NA & NA & NA & $\mathrm{NA}$ \\
\hline 8000 & NA & NA & NA & 8000 & & 8000 \\
\hline $\mathrm{C}$ & $\mathrm{H}$ & $\mathrm{H}$ & $\mathrm{C}$ & $\mathrm{H}$ & $\mathrm{H}$ & $\mathrm{H}$ \\
\hline NA & $5.5 \mathrm{hrs}$ & $5.5 \mathrm{hrs}$ & $5.5 \mathrm{hrs}$ & NA & $\mathrm{NA}$ & $\mathrm{NA}$ \\
\hline $\mathrm{NA}$ & $10-15$ min tota & 10-15 min tota & 30 min total & $2 \mathrm{~min}$ & $2 \min$ & $2 \mathrm{~min}$ \\
\hline $\mathrm{C}$ & $\mathrm{E}$ & $\mathrm{M}$ & $\mathrm{M}$ & $\mathrm{M}$ & $\mathrm{M}$ & $\mathrm{M}$ \\
\hline NA & NA & NA & NA & $1 \mathrm{~min}$ & $1 \mathrm{~min}$ & $1 \mathrm{~min}$ \\
\hline 20-118 fpm & $30 \mathrm{fpm}$ & $30 \mathrm{fpm}$ & $15 \mathrm{fpm}$ & $55 \mathrm{fpm}$ & $55 \mathrm{fpm}$ & $55 \mathrm{fpm}$ \\
\hline $\mathrm{H}$ & $\mathrm{H}$ and tailer & $\mathrm{H}$ and tailer & $\mathrm{M}$ & $\begin{array}{c}\mathrm{H} \text { and } \\
\text { equilizer }\end{array}$ & cross fed? & $\begin{array}{c}\mathrm{H} \text { and } \\
\text { equilizer }\end{array}$ \\
\hline 5 & NA & $\mathrm{NA}$ & NA & 2 & 2 & 2 \\
\hline 2 & 1 & 1 & 1 & 2 & 2 & 2 \\
\hline 295000 & $10,000-12,000$ & $6000-8000$ & $6000-8000$ & 508,320 & 451,800 & 462,240 \\
\hline NA & NA & NA & NA & $75 \%$ & $75 \%$ & $75 \%$ \\
\hline NA & $\begin{array}{c}10-20 \\
\text { changeovers/ } \\
\text { day }\end{array}$ & 5-10/day & 1/day & 2 & 2 & 2 \\
\hline NA & \multicolumn{3}{|c|}{5000 total for the three machines } & NA & NA & NA \\
\hline NA & \multicolumn{3}{|c|}{15000 total for the three machines } & NA & NA & NA \\
\hline NA & NA & NA & NA & NA & NA & NA \\
\hline $\begin{array}{c}\text { Oak, Soft } \\
\text { Maple, Hard } \\
\text { Maple }\end{array}$ & hardwoods & hardwoods & hardwoods & $\begin{array}{c}\text { Red oak, soft } \\
\text { maple, } \\
\text { cherry, hard } \\
\text { maple, alder, } \\
\text {... }\end{array}$ & $\begin{array}{c}\text { Red oak, soft } \\
\text { maple, } \\
\text { cherry, hard } \\
\text { maple, alder, } \\
\text {... }\end{array}$ & $\begin{array}{l}\text { Red oak, soft } \\
\text { maple, } \\
\text { cherry, hard } \\
\text { maple, alder, } \\
\text {... }\end{array}$ \\
\hline $\begin{array}{c}\text { Kitchen } \\
\text { cabinet } \\
\text { components }\end{array}$ & $\begin{array}{l}\text { Furniture } \\
\text { parts }\end{array}$ & $\begin{array}{c}\text { Furniture } \\
\text { parts }\end{array}$ & $\begin{array}{c}\text { Furniture } \\
\text { parts }\end{array}$ & all & all & all \\
\hline $8 / 1 / 1 / 2.5$ & NA & NA & NA & 9-96" & random & 9-96" \\
\hline 0.1875 & NA & NA & NA & \begin{tabular}{|c|}
$11 / 8 "$ \\
thickness, $1 / 8$ \\
width
\end{tabular} & \begin{tabular}{|c|}
$11 / 8 "$ \\
thickness, $1 / 8$ \\
width
\end{tabular} & $\begin{array}{c}11 / 8 " \\
\text { thickness, } 1 / 8 \\
\text { width }\end{array}$ \\
\hline
\end{tabular}




\begin{tabular}{|c|c|c|c|}
\hline Moulder 12 & \begin{tabular}{|l|} 
Moulder 13 \\
\end{tabular} & Moulder 14 & \begin{tabular}{|l|} 
Moulder 15 \\
\end{tabular} \\
\hline 6/D & 6/F & $5 / \mathrm{B}$ & $5 / B$ \\
\hline NA & NA & NA & NA \\
\hline NA & NA & NA & NA \\
\hline 6000 & 6000 & 6000 & 8000 \\
\hline $\mathrm{H}$ & $\mathrm{H}$ & $\mathrm{H}$ & $\mathrm{H}$ \\
\hline NA & NA & NA & NA \\
\hline $2 \min$ & $2 \min$ & $2 \min$ & $2 \min$ \\
\hline M & M & M & M \\
\hline 1 min & 1 min & $1 \mathrm{~min}$ & 1 min \\
\hline $120 \mathrm{fpm}$ & $45 \mathrm{fpm}$ & $45 \mathrm{fpm}$ & $55 \mathrm{fpm}$ \\
\hline $\begin{array}{c}\mathrm{H} \text { and } \\
\text { equilizer }\end{array}$ & $\begin{array}{c}\mathrm{H} \text { and } \\
\text { equilizer }\end{array}$ & $\begin{array}{c}\mathrm{H} \text { and } \\
\text { equilizer }\end{array}$ & $\begin{array}{c}\mathrm{H} \text { and } \\
\text { equilizer }\end{array}$ \\
\hline 2 & 2 & 2 & 2 \\
\hline 2 & 2 & 2 & 2 \\
\hline 671,040 & 339,840 & 495,360 & 502,560 \\
\hline $75 \%$ & $75 \%$ & $75 \%$ & $75 \%$ \\
\hline 2 & 2 & 2 & 2 \\
\hline NA & NA & NA & NA \\
\hline NA & NA & NA & NA \\
\hline NA & NA & NA & NA \\
\hline $\begin{array}{c}\text { Red oak, soft } \\
\text { maple, } \\
\text { cherry, hard } \\
\text { maple, alder, } \\
\ldots \\
\end{array}$ & \begin{tabular}{|c} 
Red oak, soft \\
maple, \\
cherry, hard \\
maple, alder, \\
.. \\
\end{tabular} & $\begin{array}{c}\text { Red oak, soft } \\
\text { maple, } \\
\text { cherry, hard } \\
\text { maple, alder, } \\
\text {... } \\
\end{array}$ & $\begin{array}{c}\text { Red oak, soft } \\
\text { maple, } \\
\text { cherry, hard } \\
\text { maple, alder, } \\
\text {... } \\
\end{array}$ \\
\hline $\begin{array}{c}\text { mostly face } \\
\text { frame }\end{array}$ & all & all & $\begin{array}{l}\text { mostly face } \\
\text { frame }\end{array}$ \\
\hline 9-96" & 9-96" & 9-96" & 9-96" \\
\hline $11 / 8^{\prime \prime}$ & $11 / 8^{\prime \prime}$ & $11 / 8^{\prime \prime}$ & $11 / 8^{\prime \prime}$ \\
\hline $\begin{array}{c}\text { thickness, } 1 / 8 \\
\text { width }\end{array}$ & $\begin{array}{c}\text { thickness, } 1 / 8 \\
\text { width }\end{array}$ & $\begin{array}{c}\text { thickness, } 1 / 8 \\
\text { width }\end{array}$ & $\begin{array}{c}\text { thickness, } 1 / 8 \\
\text { width }\end{array}$ \\
\hline
\end{tabular}


Cell: A7

Comment: Spindle Configuration:

Look at the "Spindle Configuration" sheet, then enter the letter that corresponds to your moulder configuration.

Cell: A12

Comment: Tool room time: Refers to the time it takes to prepare the tool and grind it.

Cell: A13

Comment: Setup time for tools:

Refers to the time it takes to mount the tool on the machine.

Cell: A14

Comment: Spindle positioning indicators:

Please indicate if you have a combination of systems, how many spindles have each system.

Cell: A16

Comment: Actual feed rate: It is the speed at which the machine normally runs.

Cell: A21

Comment: Effective Machining Time: It is the time the machine is actually running and producing parts (no idle time).

Cell: A23

Comment: Machine Maintenance Expenses: Is how much is spent in oil, spare parts, labor, etc. for the machine.

Cell: A24

Comment: Tool Expenses: Refers to purchase of knives.

Cell: A25

Comment: Tool Maintenance Expenses: It is the amount spent in grinding wheels, tool spare parts, etc. for the tools.

Cell: A26

Comment: Workpiece materials: oak, cherry, maple, poplar, pine, plastic, mdf, composites, etc.

Cell: A27

Comment: Product type: flooring, millwork, mouldings, cabinet parts, furniture parts, siding, construction lumber, etc.

Cell: A29

Comment: Material removed:

Difference between the rough dimensions and the end profile. 